Article

\title{
A CityGML Multiscale Approach for the Conservation and Management of Cultural Heritage: The Case Study of the Old Town of Taranto (Italy)
}

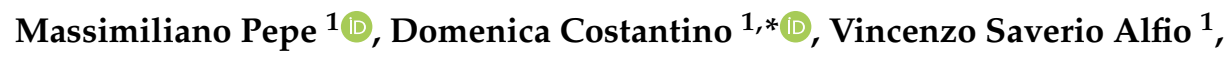 \\ Maria Giuseppa Angelini ${ }^{1}\left[\right.$ and Alfredo Restuccia Garofalo ${ }^{2}$ \\ 1 Polytechnic of Bari, 70125 Bari, Italy; massimiliano.pepe@poliba.it (M.P.); \\ vincenzosaverio.alfio@poliba.it (V.S.A.); mariagiuseppa.angelini@poliba.it (M.G.A.) \\ 2 AESEI Spin-off-Polytechnic of Bari, 74015 Martina Franca (Taranto), Italy; ingrestucciachristian@gmail.com \\ * Correspondence: domenica.costantino@poliba.it
}

Received: 19 May 2020; Accepted: 15 July 2020; Published: 17 July 2020

\begin{abstract}
The aim of this article is to provide a dedicated approach to the realisation of a CityGML model for the valorisation and the conservation of existing cultural heritage. In particular, for the ancient city of Taranto (Italy), several levels of details (LODs) have been built. CityGML models in LOD1 for the most representative periods were realised, which were characterised by urban changes from the mid-1800s until today. To achieve this aim, great importance was devoted to the process of integration of the different file formats. A geographic information system (GIS) approach has been put in place for the construction of the CityGML model in LOD1. In addition, the study also focused on the realisation of a CityGML model in LOD3 of a bridge of a particular historical and architectural interest, called "Ponte di Porta Napoli", also situated in the city of Taranto. In the latter case, the CityGML model was realised starting from the geomatics survey. Therefore, the project structured in this way represents an important tool for the sharing of (georeferenced) territorial information. The CityGML models represent a valid support for spatial planning processes and measures for the protection, monitoring and conservation of urban elements.
\end{abstract}

Keywords: 3D city model; LOD; cultural heritage; historical maps; urban GIS

\section{Introduction}

The management and protection of the cultural heritage of a city through digital tools is an objective to safeguard the evidence of the past and then pass it on to future generations, preserving the identity of a place and its population. Indeed, human-induced urban transformations or land changes due to various natural factors have led to changes in the appearance and shape of urban centres [1,2].

Although most historic city centres rely on a static urban fabric, there are still, over the decades, changes that risk losing the sense of place, connectivity and social fabric, environmental integrity and cultural foundations. In recent years, we are observing alarming losses of urban identity, due to the poor protection of historic centres. The concept of urban conservation includes the preservation of the character and the historical urban form of a community, the architectural quality of its structures, its street patterns, its furnishings and other physical characteristics. The main focus of conservation is on the protection and maintenance of ancient buildings and monuments of a historical and architectural importance or interest, but it is necessary to pay attention to the interaction of this heritage with the urban fabric which it is integrated into.

The conservation process must aim at the wise and beneficial use of the natural, building, human and financial resources where the monument is contextualised. Therefore, in order to preserve the 
historical and cultural heritage of an ancient urban centre, it must be considered, from a social and economic point of view, as integrated into a single and unified process according to agreed planning policies. Consequently, in preserving the features of an urban area, it is necessary to focus the attention on the urban whole rather than on the architectural merit of individual buildings. The preservation of historical areas does not only mean the preservation of a valuable heritage, but also its enhancement and the harmonious integration of the old and the new city. In this context, the conservation of historical areas as part of a sustainable development programme cannot only refer to static conservation alone, but it is necessary to take into consideration the dynamic process, where the conservation of urban heritage becomes a means and an integral component of actions.

Through a digital representation, the historical evolution of the urban centre was evaluated in order to identify the changes and define the recovery and conservation interventions.

The 3D city models represent a valid tool to manage and visualize the city in a specific period and, at same time, to analyse the change over the years. Indeed, the 3D city models of urban areas allow the modelling of terrain, buildings, bridges, vegetation, infrastructures, etc.

Different methods and techniques have been developed for the 3D representation of cities, such as the extrusion of building footprints from airborne laser scanner (ALS) data [3] or the use of oblique aerial images in order to extract a 3D urban model [4]. It is possible to build 3D models of cities with hybrid ALS-photogrammetric sensors [5]. In particular, from a photogrammetric point of view, the possibility to build textured 3D models of buildings using algorithms based on structure from motion (SfM)/multi-view stereo (MVS) has been evaluated: these approaches lead to a 3D object of the city in a specific reference system but do not provide any semantic information. Besides the use of sensors on aerial platforms, 3D city models can also be obtained by terrestrial means; for example, StreetMapper is a dynamic 3D mapping system that uses the very latest laser scanning technology from Riegl Company. The latter features four 2D laser scanners integrated with a high performance of global navigation system satellite (GNSS) and inertial navigation system: this configuration allows an efficient collection of dense and area-covering 3D point clouds also in urban environments [6]. Another approach is based on georeferenced 3D image collections of multi-view stereo; indeed, thanks to the use of these cameras connected with GNSS/inertial systems, it is possible to obtain the position and attitude of each image; therefore, using image-matching algorithms, it is possible to build 3D models of urban areas [7].

CityGML, an Open Geospatial Consortium (OGC) standard 3D data format, has been developed for presenting city models with semantic data [8]. CityGML is a common semantic information model for the representation of 3D urban objects that can be shared over different applications [9]. In particular, it is possible to obtain five well-defined consecutive levels of detail: LOD0-regional, landscape; LOD1—city, region; LOD2—city districts, projects; LOD3—architectural models (outside), landmarks; and LOD4-architectural models (interior).

The 3D CityGML model approach was applied in several cities, such as for the construction of the model of Berlin (German) [10] or for the city of Istanbul (Turkey) [11]. For the construction of the city of Vienna (Austria), an integrated, semantic, 3D and CityGML-based virtual model was realised [12]. The freely available 3D geospatial data of Prague (Czech Republic) was built through the transformation from the proprietary data format into the open data model [13].

The aim of the paper is to identify a suitable methodology able to evaluate the urban evolution of a part of the old city of Taranto and the construction of a 3D CityGML model at the LOD1 level for buildings and land, while at the LOD3 level for a bridge of a particular historical-architectural-urban interest.

\section{Method}

The construction of the 3D city model, which aims to describe from a geometric and semantic point of view the specific urban area, can be realised through the following steps:

- Research and analysis of cartographic and iconographic documentation (see Section 3.2.1); 
- Georeferencing of maps and spatial configuration of the object deduced from historical documentation (see Section 3.2.2);

- Building vector files of the several time periods to obtain 3D models (see Section 3.2.3);

- Building an Environmental Systems Research Institute (ESRI) shapefile (polygon) of the features that characterise the urban area, such as buildings and bridges (see Section 3.2.3);

- Transformation of the file into the CityGML model (see Section 3.2.3).

As regards the first step, in order to reconstruct the historical evolution, it is necessary to collect a series of graphic and iconographic documents consisting of the repertory of views and representations of the city, the corpus of photographic images and the fund of documents/graphs related to the events of the city preserved in the State Archives of Taranto and the Municipal Historical Archives.

The next step, the georeferencing of each map, is of fundamental importance because it is possible not only to have the entire cartographic collection available in a single reference system, but also represents a valid tool to visualise and determine the historical evolution of the urban environment.

For each identified epoch, in the ArcGIS software, namely a geographic information system (GIS) to work with maps and geographic information maintained by the Environmental Systems Research Institute (ESRI), it is possible to vectorise the respective cartography creating a separate ESRI shapefile for every reference era and associate a polygonal feature of the urban elements of the city. In particular, the shape of the buildings has been obtained from the most recent available cartography with a submetric accuracy compatible with the scale of the representation, as described in Section 3.2.2 (reference cartography). Subsequently, in the GIS environment, the shape of the buildings was compared with the shape of the maps organised in a decreasing way by reference period; in the event that new structures were demolished or built, the basic cartography was changed.

In this way, it is possible to combine geometric information with height data and thus create a database with different collected and contextualised information layers: buildings, boundary walls and other essential elements of the territory, but also destination of use and time of construction can be categorised, represented and displayed in the vector world. With the last period taken into consideration, the height of the buildings was derived from numerical cartography. For previous periods, the height of the buildings was obtained by visual and qualitative analysis of iconographic and historical sources.

Once the data have been appropriately coded, it is possible to build a 3D view through the ArcScene application of the ArcGIS system [14]. With this application in fact, the 2D ESRI shapefiles containing the relative altimetric information can be visualised in 3D view by referencing the relative value contained in the field. The level of visualisation is completed by the different categorisations and dressings; these parameters can be set in order to have an easier and more contextualized reading of the 3D environment. Taking into account the physical surface area of the land including buildings, artificial structures, trees and other natural elements, a digital surface model (DSM) is obtained. In this case study, we focus our attention only on the anthropic elements (bridges, buildings, piers and walls).

The advantage of using a platform such as ArcGIS for the realisation of a 3D model consists in the versatility that the same platform offers; in fact, once the different maps for each era have been reconstructed, through simple map algebra operations, it is possible to verify the changes that have occurred over the years and, consequently, obtain historical information on each building. In this way, it is possible to obtain a representation in $4 \mathrm{D}$ of the city and, at the same time, establish the time of construction of the individual building (see Section 3.2.4).

The model thus obtained certainly represents a valid support, for example, for the different levels of planning on an urban scale or as an alternative to environmental monitoring studies. Therefore, it is possible to build an ESRI shapefile, which contains geometric and semantic information of the urban elements within the study area; in addition, taking into account an adequate digital terrain model (DTM), it is possible to realise the transformation into CityGML at the LOD1 level.

However, in order to improve the quality of the city model, one can apply a level of detail (LOD3) to the masonry bridge connecting the island to the mainland of a particular historical-architectural 
value. The information provided in the various maps does not allow an adequate representation of the bridge. Therefore, for an appropriate geometric representation of the architectural structure, it is needed to carry out a geomatics survey using the laser scanner technique. Once the point cloud has been obtained, it is required to modify the data to construct parametric objects of the different elements that characterise the structure and will constitute the different levels of detail in the 3D representation. These objects are transformed, in turn, into the CityGML model using commercial software (FME-Feature Manipulation Engine developed and distributed by Safe Software Company).

The developed method can be summarized in the following pipeline (Figure 1).

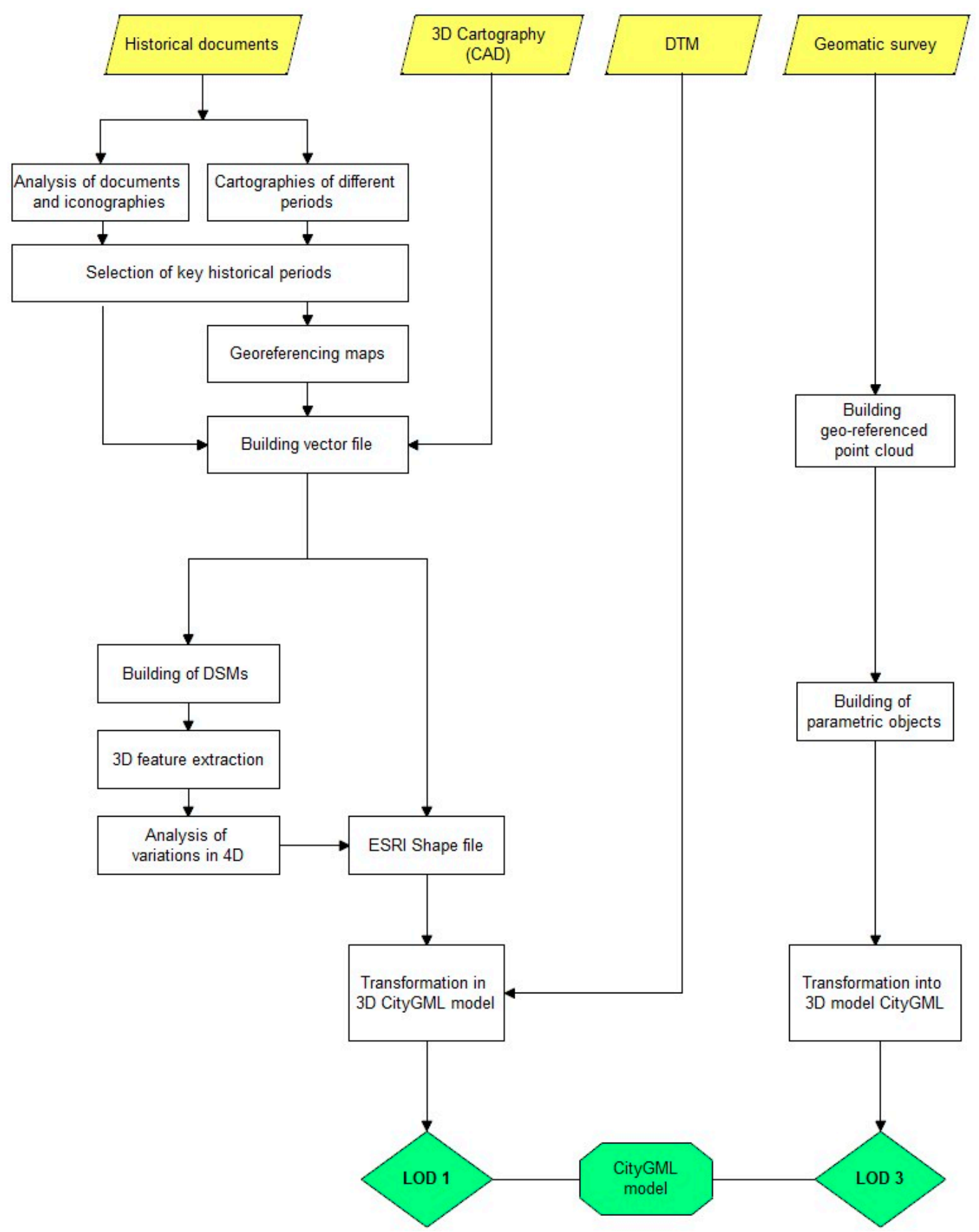

Figure 1. Pipeline of the developed method. 


\section{Case Study}

\subsection{Study Area and Brief History}

The study area concerns part of the old town (or also known by the term "Città Vecchia") of the city of Taranto, which is a coastal city in Apulia, Southern Italy (Figure 2a). The city of Taranto, located in the centre of the homonymous gulf, rises on a strip of land between two seas: the outer one, Mar Grande, is delimited by the Cheradi Islands and joins the inner one, Mar Piccolo, through two channels, one natural to the west of the island, on which the historical city rises, and one artificial to the east in the direction of Lecce (Figure 2b). The old town of Taranto is an island of about 30 hectares (Figure 2c) that is connected to the land by two bridges: the "Ponte di Porta Napoli" (or "Ponte di Pietra") bridge in the north which connects it to the "Tamburi-Croce" district, and the "Ponte Girevole" bridge in the south which connects it to the new town, the liveliest and commercial area of the city. The old town stands on a portion of land currently isolated from the mainland, while the modern city is located on the two portions of land forming the eastern village outside the two bridges (Figure 2c).

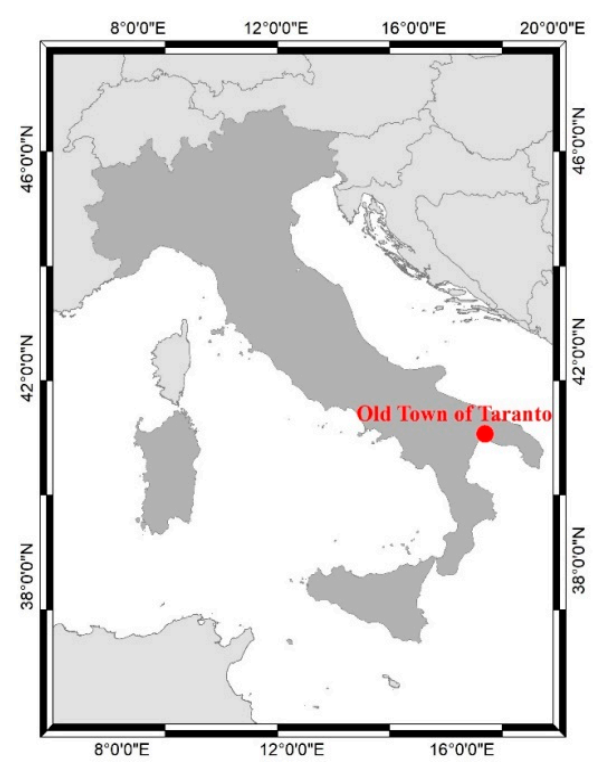

(a)

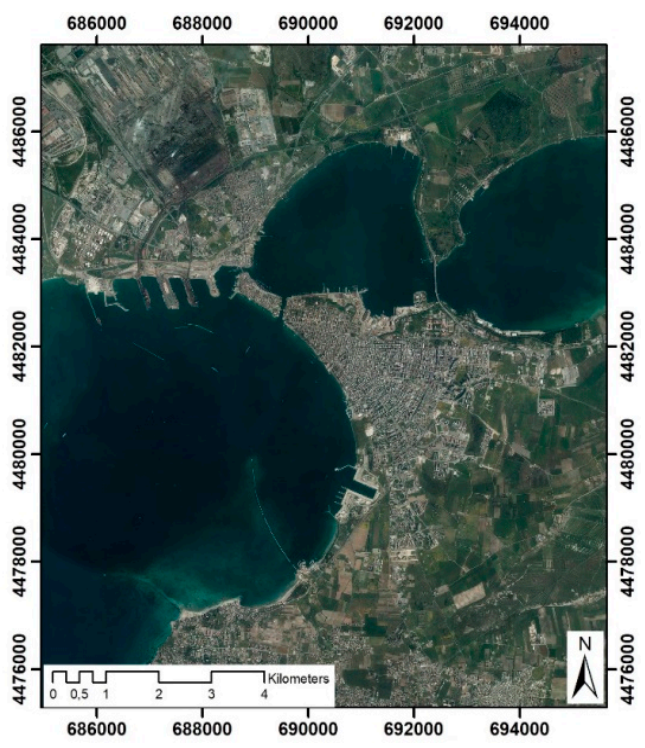

(b)

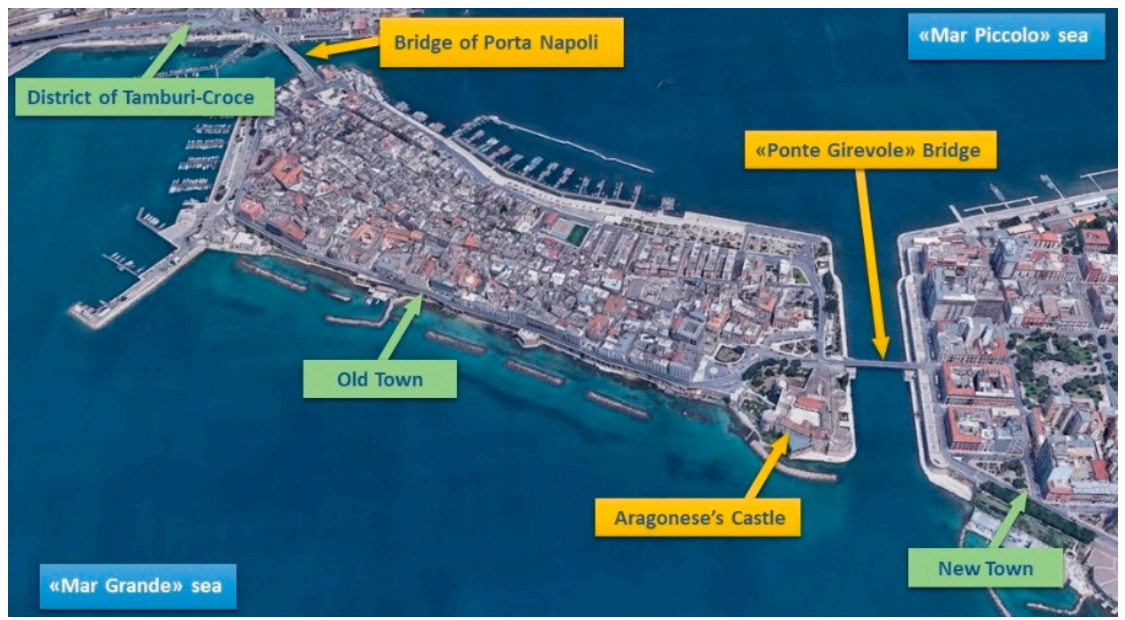

(c)

Figure 2. The study area: (a) location; (b) orthophoto in UTM33-WGS84 of the Taranto city; (c) panoramic image of the old town of Taranto. 
The old town or "Città Vecchia" is where the Greeks built their acropolis. Today, it retains the same street layout of 967, when the Byzantines under Nicephorus Phocas rebuilt what the Saracen troops led by the Slavic Sabir had razed to the ground in 927 AD. There are four main arteries that run in a straight direction, but the side streets were specially built narrow and winding to prevent the passage of an invading army. In 1746, the entire population of Taranto resided in the old town, leading to a vertical development of the town itself. Between 1865 and 1889, during the era of the great industrialization, the Military Arsenal was built, and from an economic point of view, the old town had a rapid evolution that saw the population of Taranto, always devoted only to fishing, gradually incorporated into the new sector that did not require a residence on the island. Thus began a progressive depopulation of the island. Later, from 1934, the Italian government undertook a redevelopment project that led to the demolition of the old medieval city walls and three out of four churches in the area and these activities to change the city continued until the outbreak of World War II. On the demolished areas, some buildings were rebuilt and some squares inside the old town were modified [15].

\subsection{The Source Data}

\subsubsection{Iconographic Analysis of the Urban Evolution from the First Century A.D. to the Present Day}

The historical reconstruction of the city takes place through the study and analysis of historical, iconographic and cartographic documents. The iconographic and historical study, carried out by consulting various sources, has allowed a reconstruction of the old city, starting from 967 A.D. Indeed, the present conformation of the ancient village of Taranto dates back to 967 A.D. when Niceforo II Foca eliminated the last remains of the ancient city and the acropolis, had the coastal stretch along the Mar Piccolo filled in to facilitate the work of the fishermen and built a bridge over seven arches (at the present Porta Napoli bridge) overpassing the natural canal to the north west of the city itself.

At the end of the fifteenth century, the Aragonese decided to fortify the city, building the Aragonese Castle and its moat: the succession of events, which ended with the loss of independence of the Kingdom of Naples, brought the city of Taranto under Spanish rule; nevertheless, the city decided to fortify itself by building a wall along the entire perimeter of the old city (Figure 3a), while along the coast of the Mar Grande, coastal watchtowers were built to protect the western entrance of the city.

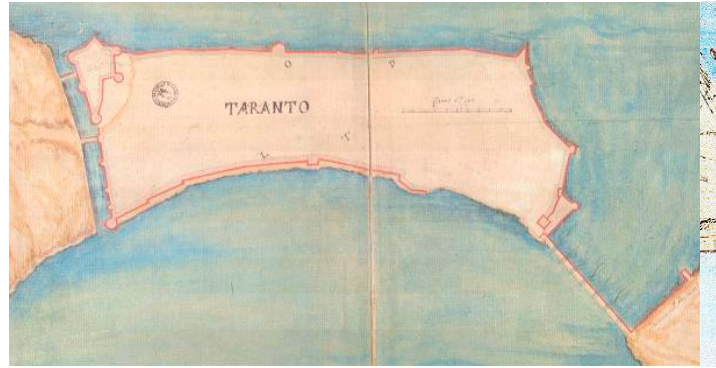

(a)

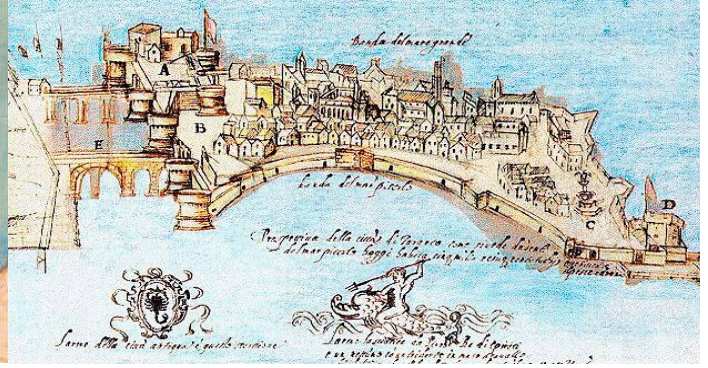

(b)

Figure 3. Iconographic maps of the fortifications of the city of Taranto (the north is downwards): (a) cartography of the second half of the XVI century and (b) reconstruction of the city of Taranto seen from the Mar Piccolo in the XVI century.

On the western front, to protect the north-western entrance of the city, the Raimondello Tower was built in 1441, a large square kept reinforced in the following years with the construction of two towers, located at the end of the city walls (Figure $3 b$ ).

In the period between the 17th and 18th centuries, the city did not undergo real morphological transformations except for the construction of the most important noble palaces, still present both on the front of the Mar Grande and inside the historical city, which led to the demolition of some districts with a consequent overcrowding of others (Figure 4a). 


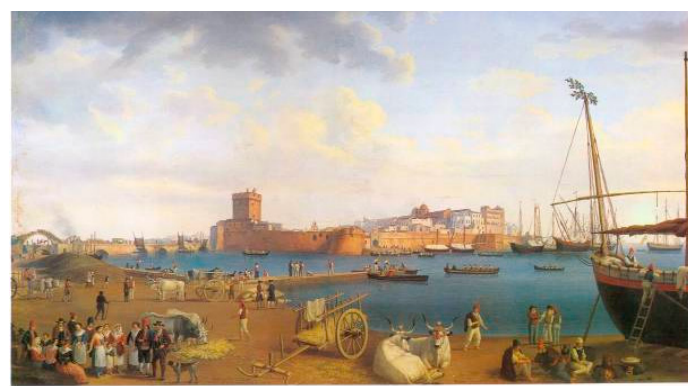

(a)

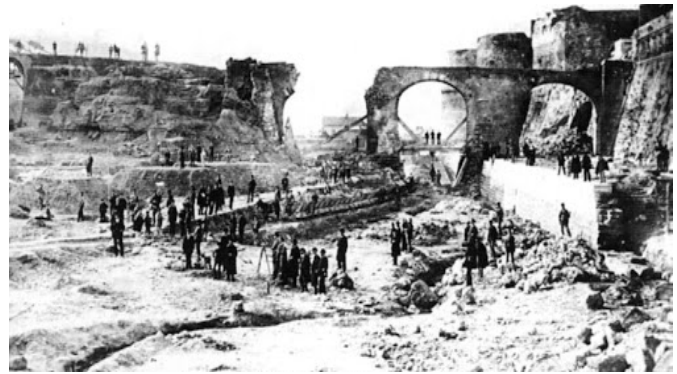

(b)

Figure 4. Ancient views of the city of Taranto: (a) view of the port in a 1789 print and (b) demolition of the castle towers and construction of the navigable canal.

In the following century, the castle took its present form: in 1883, one of the five towers that joined the curtain wall, the one dedicated to Sant'Angelo, together with the Mater Dei, Monacella and Vasto towers of the civic wall, were demolished to make space for the current navigable canal and the revolving bridge. The works were completed in 1887, the year in which the castle became the seat of the Regia Marina (Figure 4b).

Especially on the western front, the 19th century represented a period of great urban changes: the city's fortification walls were demolished, and the Citadel or Raimondello tower had become unsafe and impossible to recover, following a first flood in 1827 that caused damage to many houses and the fortification walls that surrounded the city and a second flood, in 1883, of greater violence due to the current that was created between the two seas (Figure 5a). It was at the end of the 19th century that the city of Taranto, in particular the north-western front, underwent the greatest process of urban variation, which made it similar to the present day. In fact, the new bridge of Porta Napoli was built, which with only three arches (Figure 5b) has a linear development of 115 meters and extends along a different axis from the previous one with seven arches [16,17].

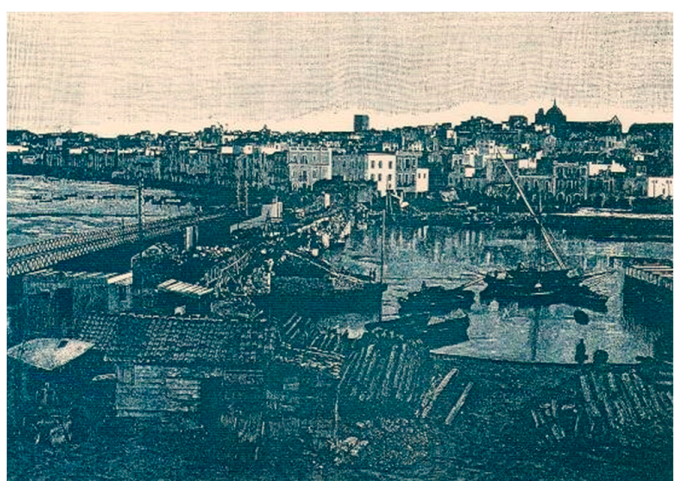

(a)

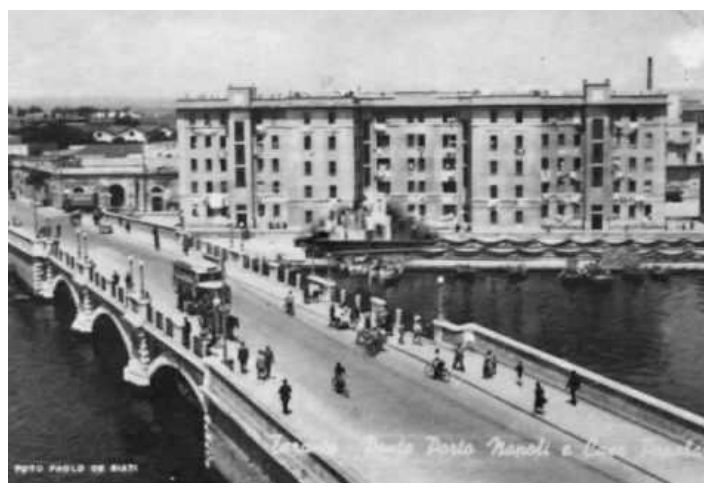

(b)

Figure 5. Historical images: (a) the western entrance of the city of Taranto following the flood of 1883; (b) the Porta Napoli bridge in a photograph from the beginning of the 20th century.

In the 1930s, also the layout of the promenade in Via Garibaldi changed, to counteract the poor hygienic, social and static conditions, all aggravated by a very high population density.

To stop this phenomenon, a series of blocks of the historic Taranto were demolished to make way for the construction of a series of buildings that could be occupied by the many expropriated people. In the same years, a complex of four buildings was built on state property by the Istituto Autonomo Case Popolari (IACP) right behind the stone bridge, which was then demolished around the 1980s because they had problems of a static nature.

The morphological conformation of the city of Taranto in the 1980s is well represented in the aerial photograph shown in Figure 6. 


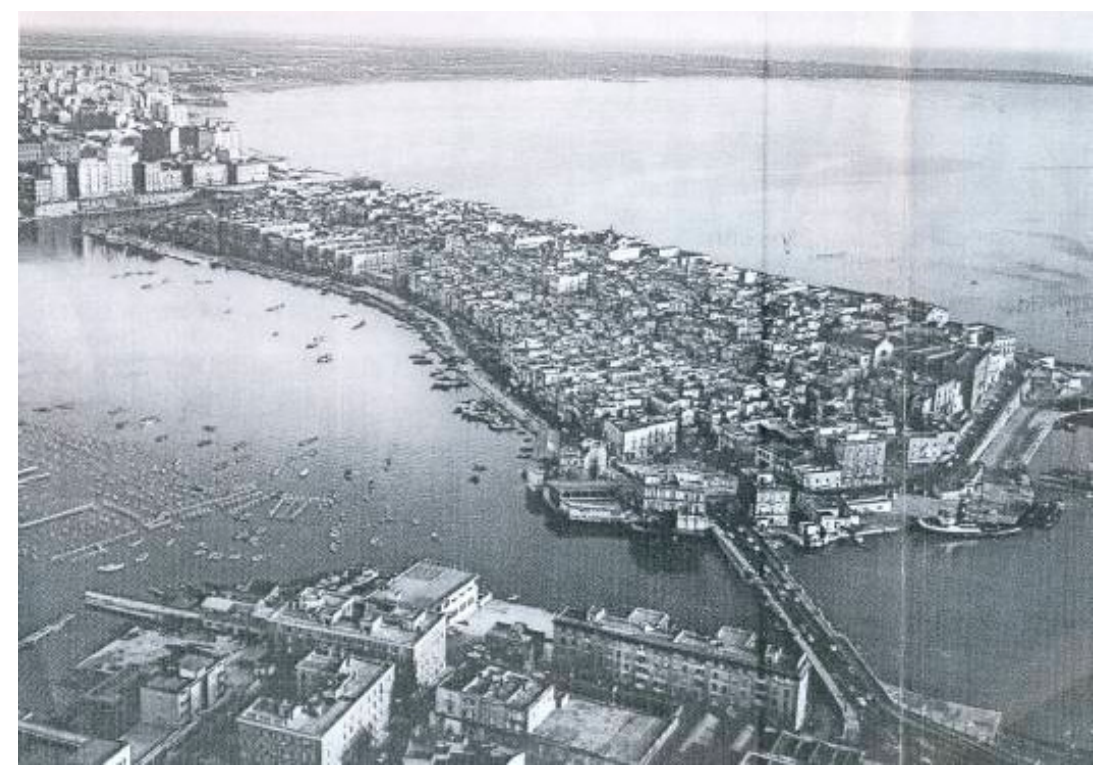

Figure 6. Aerial photography of the city of Taranto in the early 1980s.

An area that has undergone great changes over the years within the historical part of the city is the area of Piazza "Fontana". Previously the square was called Piazza Grande and was the most active square where a large daily market and several fairs took place. It changed its name to Piazza Fontana after the construction of a fountain, commissioned in 1542 by Charles V of Habsburg, King of Naples. The fountain was fed by water coming from the Triglio pipeline (an existing water source near the town of Crispiano), thus making the drinking water usable for the population. The fountain had the coat of arms of the House of Austria at the top and was characterised by an imposing set of statues (Figure 7a).

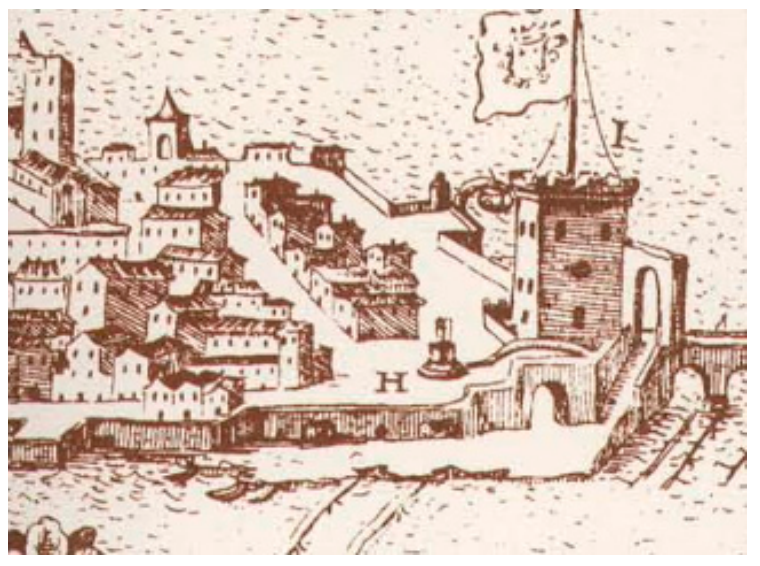

(a)

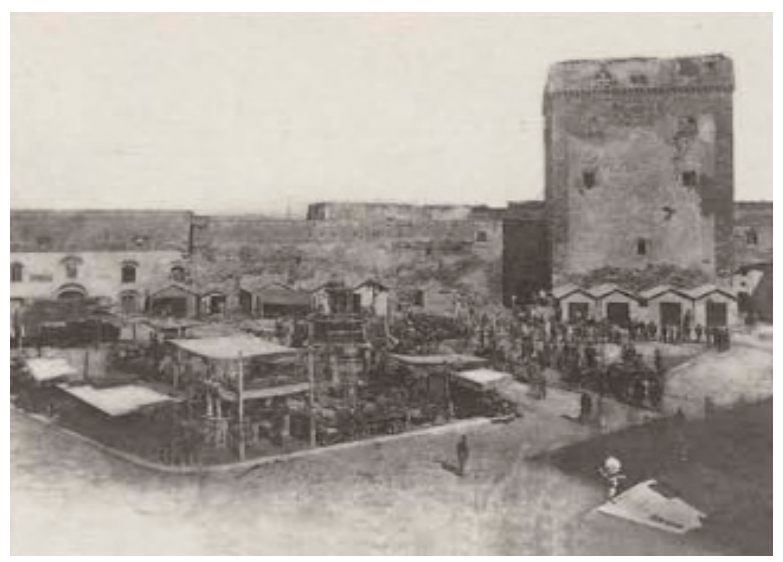

(b)

Figure 7. Iconographic reconstruction of Piazza Fontana: (a) the square in 1703; (b) in 1893.

The fountain was demolished in 1860, because, with the unrest of the unification of Italy, the population wanted to erase any memory of Austrian domination. It was replaced in 1861 by another fountain (Figure $7 \mathrm{~b}$ ) by the architect Cataldo De Florio from Taranto, but it was irreparably damaged by the famous flood in 1883. It was demolished again, presumably in 1893, and its remains were preserved for possible future reconstruction [18].

Since the beginning of the 20th century, the square has undergone a series of renovations: in fact, it seems that the square, identified by two parallel sidewalks that followed the road axis of the Porta Napoli bridge, was destined to a be market area (Figure 8a), and that, in those years, there was no 
fountain. The only urban mutation that occurred in the following decade was a significant increase in the volume of some buildings and the construction of new ones adjacent to the existing ones (Figure 8b).

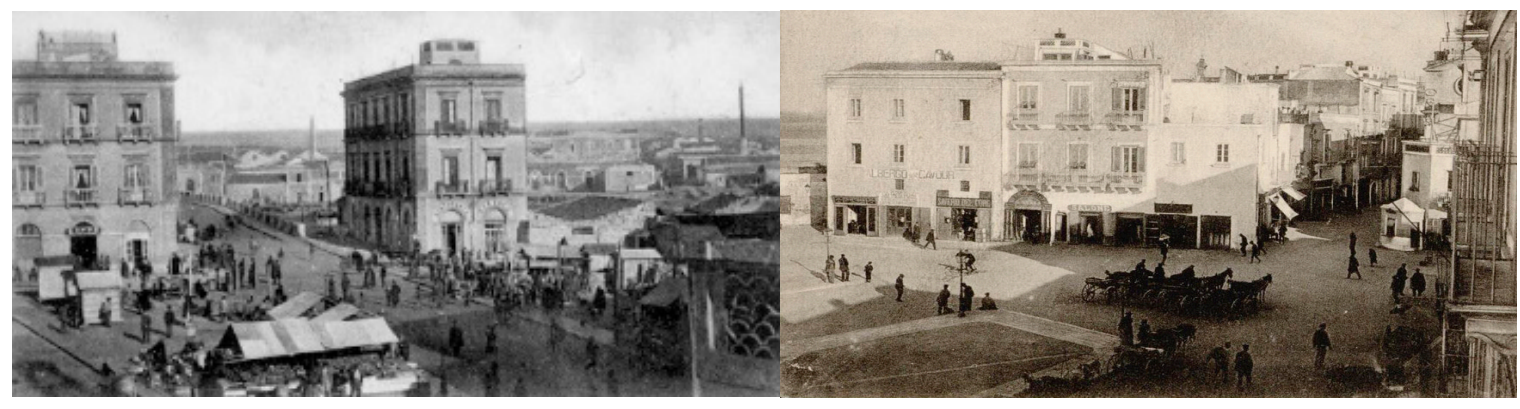

(a)

(b)

Figure 8. Photographic reconstruction of Piazza Fontana: (a) the square in 1901; (b) in 1920.

The last urban intervention of the square dates back to the 1990s, when the third and current fountain was built by the Taranto artist Nicola Carrino using some remains of the previous one demolished at the end of the 19th century. The current fountain therefore wants to recall, in its architecture, the historical memory of the city of Taranto especially in memory of the Aragonese walls that in past centuries surrounded the square itself and the industrial vocation that the city assumed in the following years [19]. In these years, the square takes on its present shape (Figure 9).

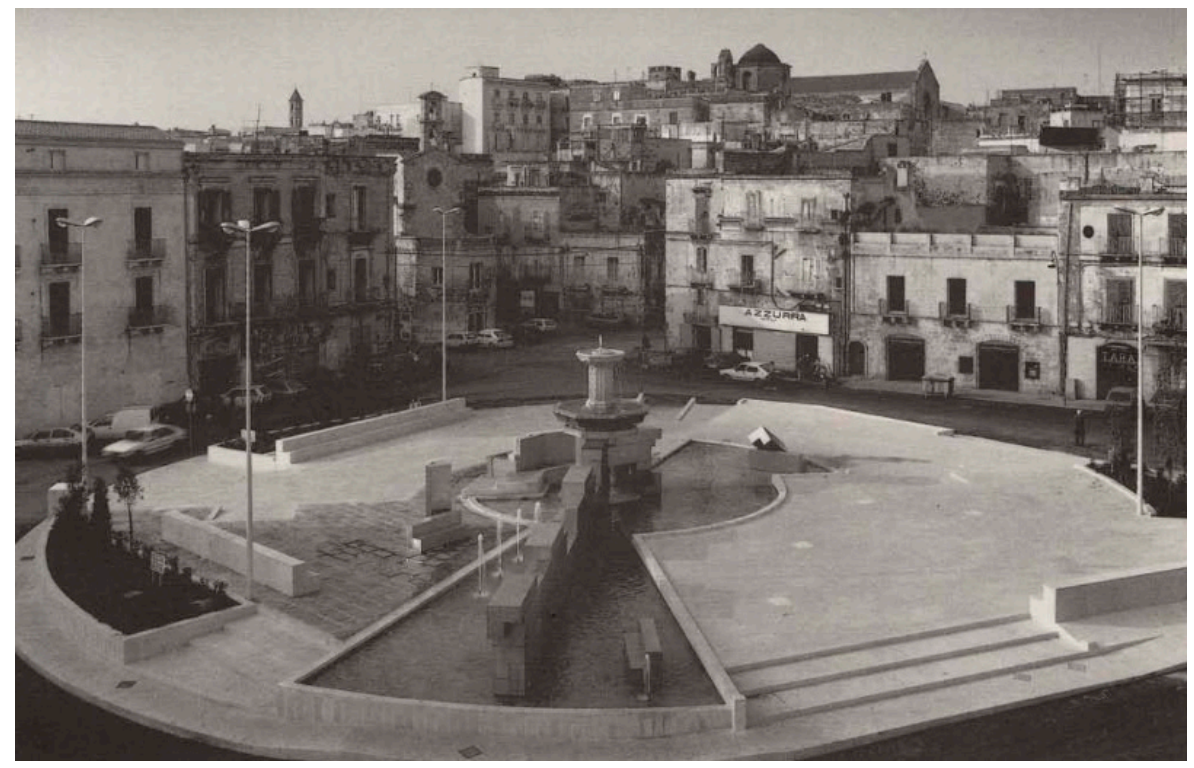

Figure 9. View of Piazza Fontana at the end of the work in the early 1990s.

\subsubsection{Evolution of the Ancient City through the Use of Historical Maps}

The historical reconstruction of the building is described in the paper through five fundamental phases, namely the pre-1806 period, from 1810 to 1860, from 1860 to 1876, from 1876 to 1910, from 1910 to 1938 and from 1938 to 2000 . These dates correspond to the identification of specific maps of the territory deduced through historical research conducted at the state archives, municipalities and the consultation of historical books.

The first map analysed is called "Map of the city and port of Taranto" (scale and reference system are unknown) and is dated 1810 (Figure 10a). This map was extracted from a historical atlas of Apulia [10]. 


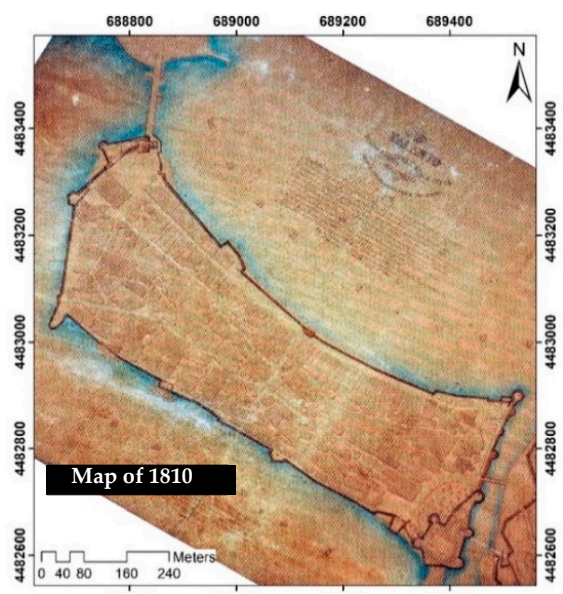

(a)

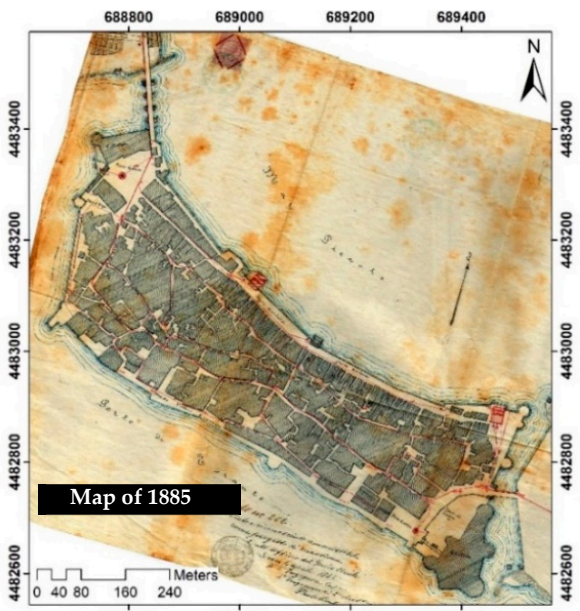

(c)

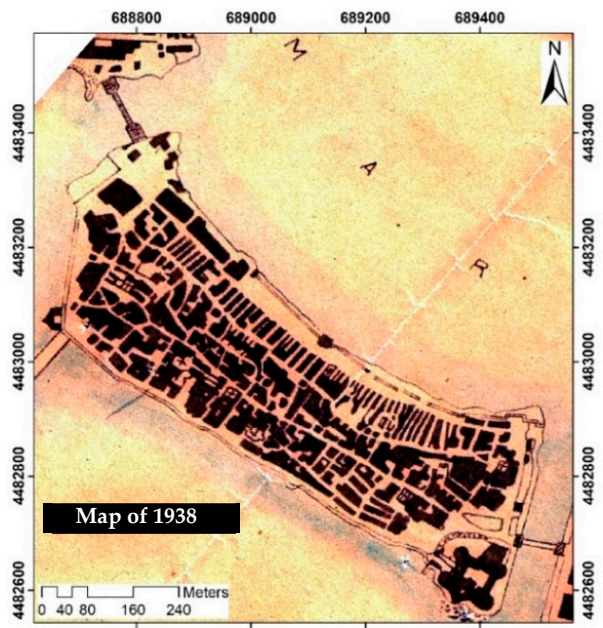

(e)

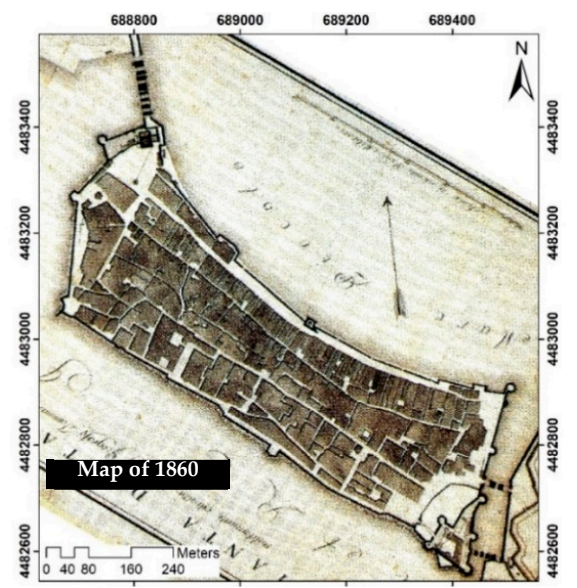

(b)

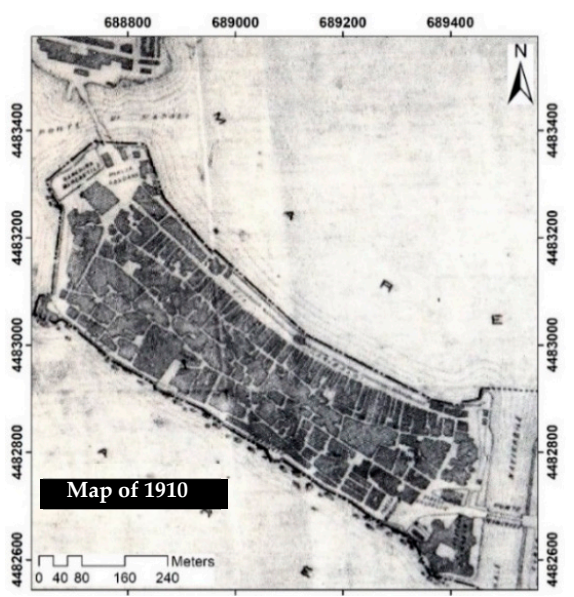

(d)

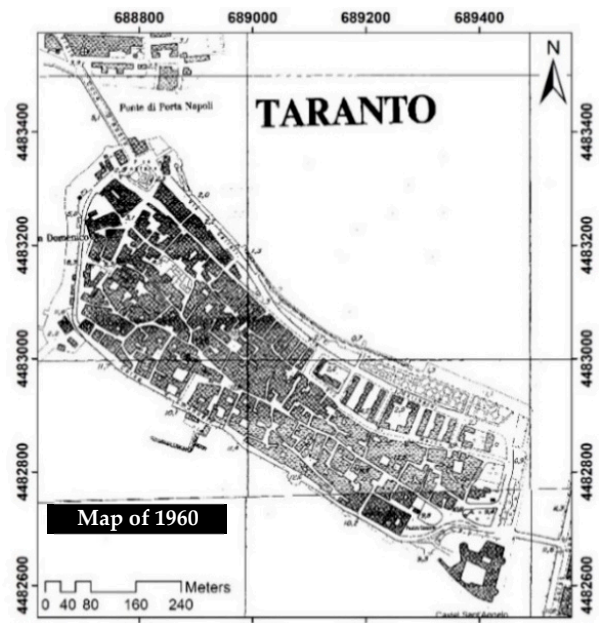

(f)

Figure 10. Georeferencing of historical maps: (a) map of 1810, (b) 1860, (c) 1885, (d) 1910, (e) 1938, (f) 1960.

The second map of the second half of the XIX century, presumably dated to 1860 (scale and reference system are unknown), was drawn up by Tommaso Zampi (Figure 10b). 
The third cartographic product taken into consideration is the map called "Pipeline and drinking water distribution" (scale and reference system are unknown) and dated 1885 (Figure 10c). This type of map was used by engineer Giovanni Galeone for the design of the aqueduct in the old town of Taranto.

The fourth map taken into consideration is dated to 1910 (scale 1:5000 and reference system unknown) and is named "Map of the city of Taranto" (Figure 10d).

The fifth map dates back to 1938 (scale and reference system are unknown) and is named "Map of the city of Taranto (Figure 10e)".

The sixth cartography, dated to 1960 (scale 1:5000; reference system Gauss-Boaga (Italy) East Zone, datum Roma40), was made by the Italian Geography Military Institute (I.G.M.I.) (Figure 10f).

The study of the historical evolution of the part of the urban area under investigation was addressed first through the identification of relevant maps showing the changes in the urban area and then through a phase of georeferencing the individual maps. However, before proceeding with the georeferencing of the maps, these documents were scanned with a resolution of $600 \mathrm{dpi}$.

In general, the transformation model can be written as [20]

$$
\begin{aligned}
& X=\sum_{j=0}^{n} \sum_{i=0}^{j} a_{j i} \cdot x^{j-1} \cdot y^{i} \\
& Y=\sum_{j=0}^{n} \sum_{i=0}^{j} b_{j i} \cdot x^{j-1} \cdot y^{i}
\end{aligned}
$$

where $x$ and $y$ are the coordinates of the source system, $n$ is the degree of polynomial and $X Y$ are the coordinates in the target system.

The higher the transformation order, the more complex the distortion that can be corrected. However, transformations higher than third order are rarely needed. Higher-order transformations require more links and, thus, will involve progressively more processing time. Therefore, in order to georeference the maps of different years, a degree of three orders of transformation was used since it allowed to obtain RMS (root mean square) errors lower than the other polynomial functions, as shown in Table 1. In particular, the transformations were performed within the ArcGIS software and framed in the UTM33-WGS84 geodetic system. The ground control points (GCPs) were obtained by the use of an orthophoto in high resolution (ground sample distance (GSD) of 30cm) acquired in the year 2015.

\begin{tabular}{|c|c|c|c|c|c|c|}
\hline \multirow[b]{2}{*}{ Maps } & \multicolumn{6}{|c|}{ Transformation } \\
\hline & \multicolumn{2}{|c|}{$\begin{array}{c}\text { 1st Order } \\
\text { Polynomial (Affine) } \\
\text { RMS Error (pixel/m) }\end{array}$} & \multicolumn{2}{|c|}{$\begin{array}{c}\text { 2nd Order } \\
\text { Polynomial } \\
\text { RMS Error (pixel/m) }\end{array}$} & \multicolumn{2}{|c|}{$\begin{array}{c}\text { 3rd Order } \\
\text { Polynomial } \\
\text { RMS Error (pixel/m) }\end{array}$} \\
\hline Map of 1810 & 11.42 & 7.080 & 9.72 & 6.026 & 7.07 & 4.383 \\
\hline Map of 1860 & 10.13 & 9.117 & 7.81 & 7.029 & 5.85 & 5.265 \\
\hline Map of 1885 & 8.52 & 7.668 & 6.58 & 5.922 & 5.80 & 5.220 \\
\hline Map of 1910 & 8.50 & 7.650 & 6.30 & 5.670 & 4.37 & 3.933 \\
\hline Map of 1938 & 7.66 & 6.894 & 5.78 & 5.202 & 3.74 & 3.366 \\
\hline Map of 1960 & 1.12 & 0.246 & 0.90 & 0.198 & 0.63 & 0.138 \\
\hline
\end{tabular}

Table 1. Results of the georeferencing of the several maps.

Since it was not possible to identify GCPs homogeneously and especially on the extreme parts of the island, it was preferred to adopt a polynomial of second degree. In fact, choosing a polynomial of three degrees, the distortions imposed in some areas of the map are too strong. As a result, the geometry of some buildings assumed an irregular behaviour. Moreover, the difference in RMS values between those obtained using second- and third-degree polynomials is minimal compared with the type of cartography used for georeferencing.

The last map taken into account is a 1:2000 scale regional technical map. This map was carried out in the year 2000 and is available in computer-aided design (CAD) format. Each element of the territory 
is represented in height; for buildings, the height in the eaves and the height of the ground are shown. The declared accuracy of this (numerical) cartography is $0.6 \mathrm{~m}$ in planimetry and $0.40 \mathrm{~m}$ in altimetry.

\subsubsection{Volume Extrusion and Terrain Modelling}

For the reconstruction of the historical part of the city of Taranto, in the different historical periods, an integrated methodological approach has been followed, starting from an in-depth historical and iconographic survey followed by a topographical study that allowed attributing to the project the real and correct dimensions.

After a historical reconstruction of the urbanistic evolution of the city, all the photographic and iconographic documents, as well as the planimetric representations at different scales, were chronologically ordered and divided in the different periods of study: this allowed, through a visual analysis, to analyse before and model after, the right spatial configuration of the single architectural elements.

Using the ArcMap and ArcScene software, the buildings, the terrain and other structures related to each period were built. The first period was the most recent cartography, since it was possible to obtain, with a scientific method, the geometries of all the buildings (in plan and especially in height) within the study area. In particular, the first step for the realisation of the model concerned the construction of the digital terrain model. The modelling of the terrain covers, like buildings, an important part of the 3D city models. The digital terrain model (DTM) can be obtained by the use of passive or active sensors. In the first case, the images are acquired with use of cameras or sensors mounted on unmanned aerial systems (UASs), airborne systems or satellite systems. A widespread active sensor used in city surveying is airborne laser scanning (ALS). ALS is an active remote sensing technique based on light detection and ranging (LiDAR) measurements from an airplane or helicopter and most recently, also from an unmanned aerial system (UAS) [21]. The ALS sensor produces not only a georeferenced point cloud but, for each point, it is also able to record the signal intensity, the number of echoes and full waveform. Consequently, it is possible to distinguish, using the suitable post-processing software, the several territorial objects (buildings, trees, power lines, etc.). In this way, it is possible to obtain a detailed DTM and, for this reason, it was used in this case study. In particular, a DTM, with a geometric resolution of $2 \times 2 \mathrm{~m}$, provided by the Italian Ministry of the Environment and Territory [22] was used. This DTM has an altimetric accuracy of $15 \mathrm{~cm}$ and a planimetric accuracy of $30 \mathrm{~cm}$. The topographic data are provided in the ESRI ASCII raster (*.asc format), as shown below (Figure 11).

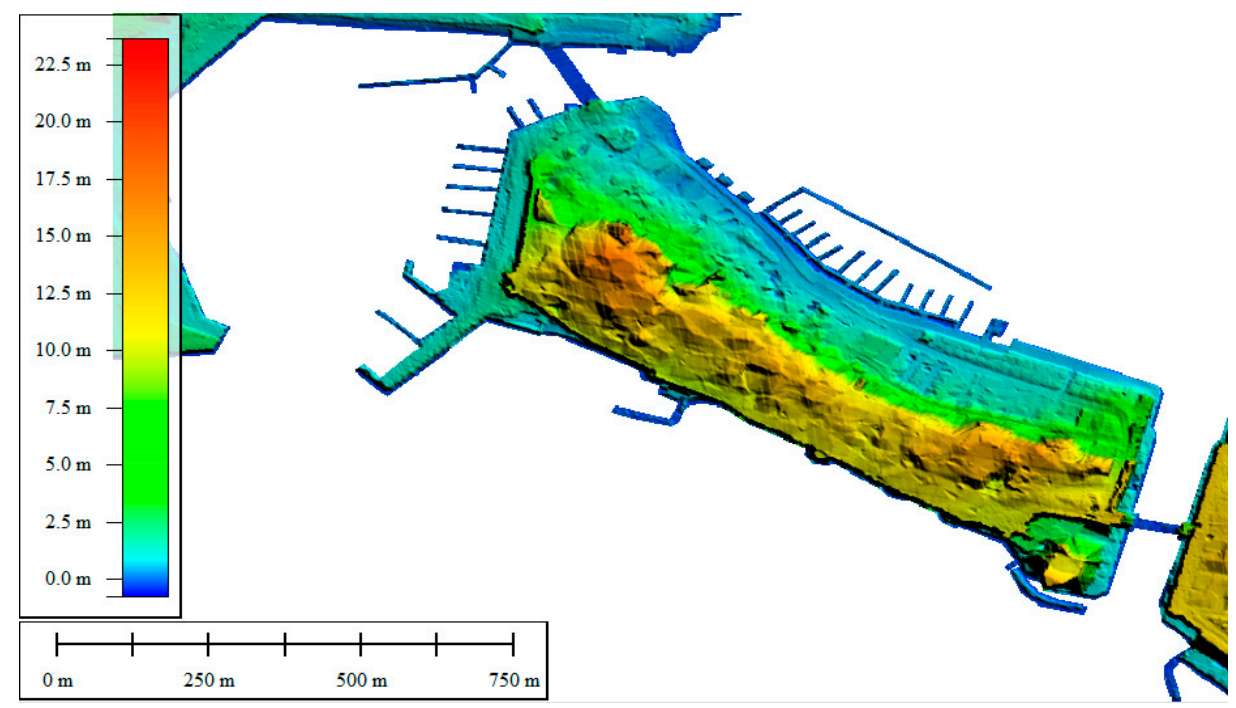

Figure 11. Digital terrain model (DTM) of study area displayed in the Global Mapper software 
The DTM was in geographical coordinates and orthometric height. Therefore, before importing the topographical data into the GIS software, the geographical coordinates were transformed into plane coordinates, i.e., UTM33-WGS84. Subsequently, the DTM format was transformed into an XYZ type file and imported in the ArcMap software: this task was carried out by means of a special tool in the Global Mapper software, which is a GIS software currently developed by Blue Marble Geographics [23].

With regard to the buildings and other historical elements, they were obtained through the extrusion of polygons. Therefore, on each map, the footprints of the buildings were designed and, subsequently, knowing the height of each building, the polygons were extruded. In order to reconstruct the heights of the architectural elements and buildings that are not present in their current state, we have analysed the images and historical iconographic documentation.

In this way, a 3D model on each map was reconstructed. As a result, a historical reconstruction in 3D was obtained, as shown below (Figures 12-14).

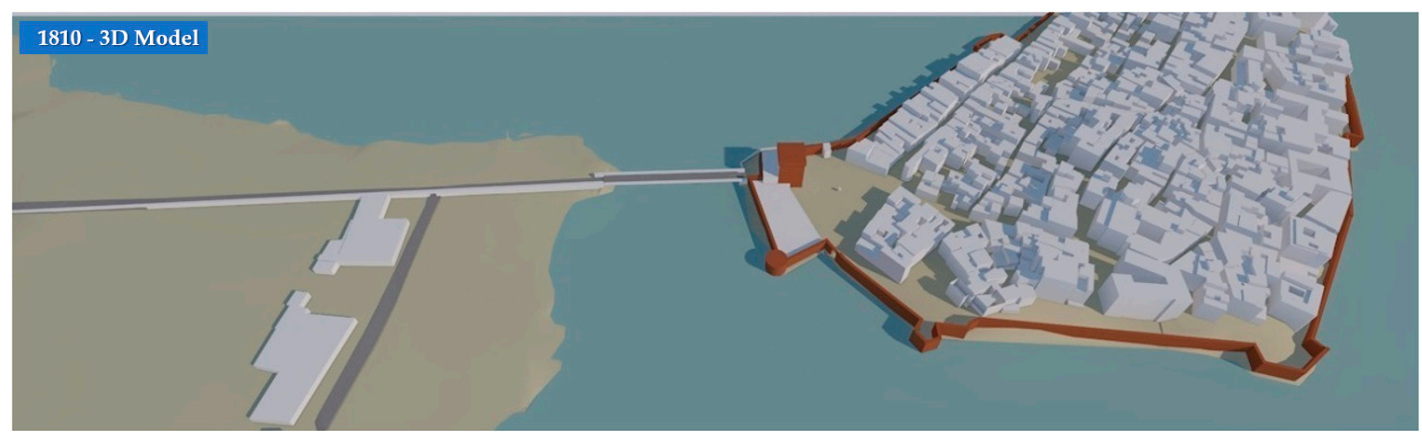

(a)

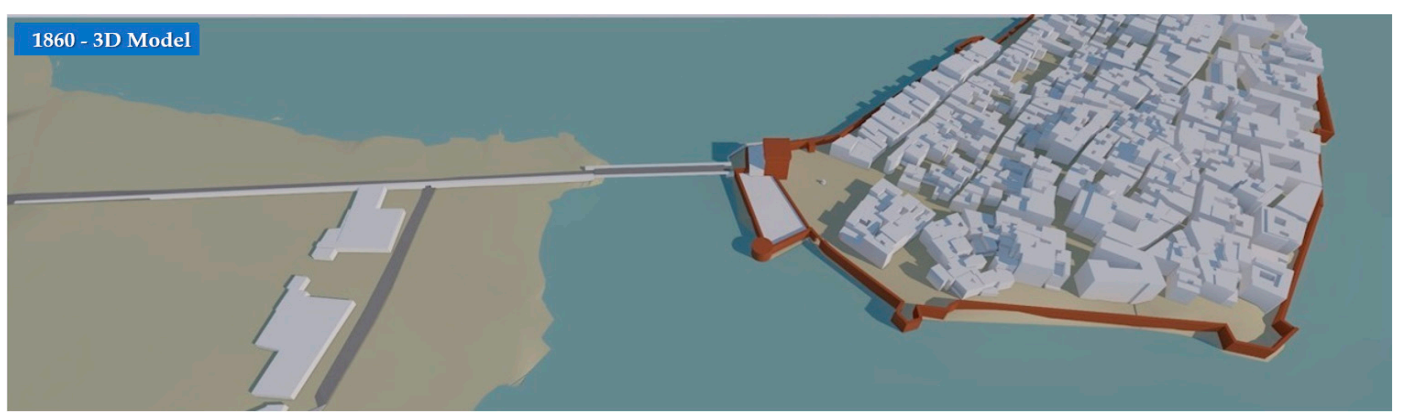

(b)

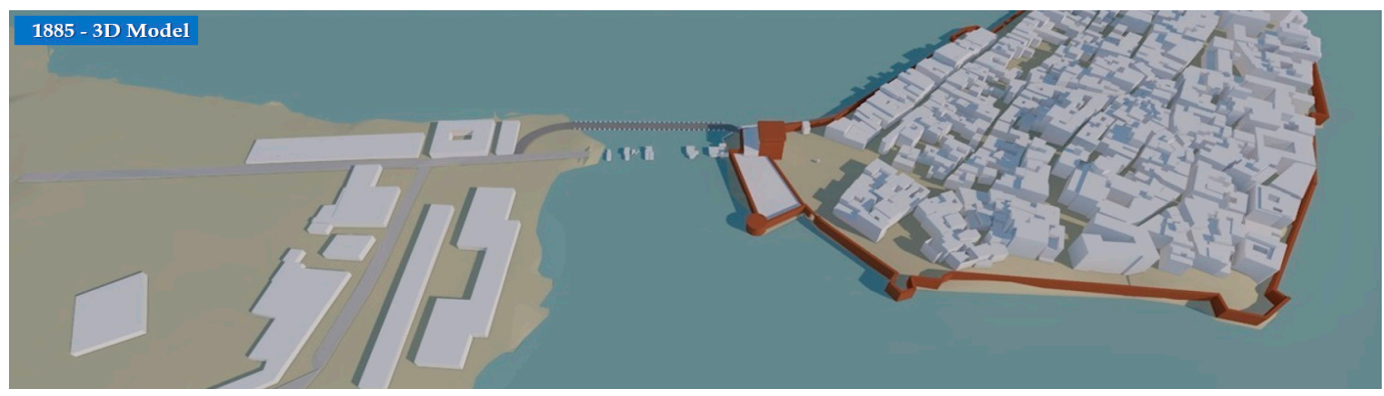

(c)

Figure 12. 3D models: (a) 1810, (b) 1860, (c) 1885. 


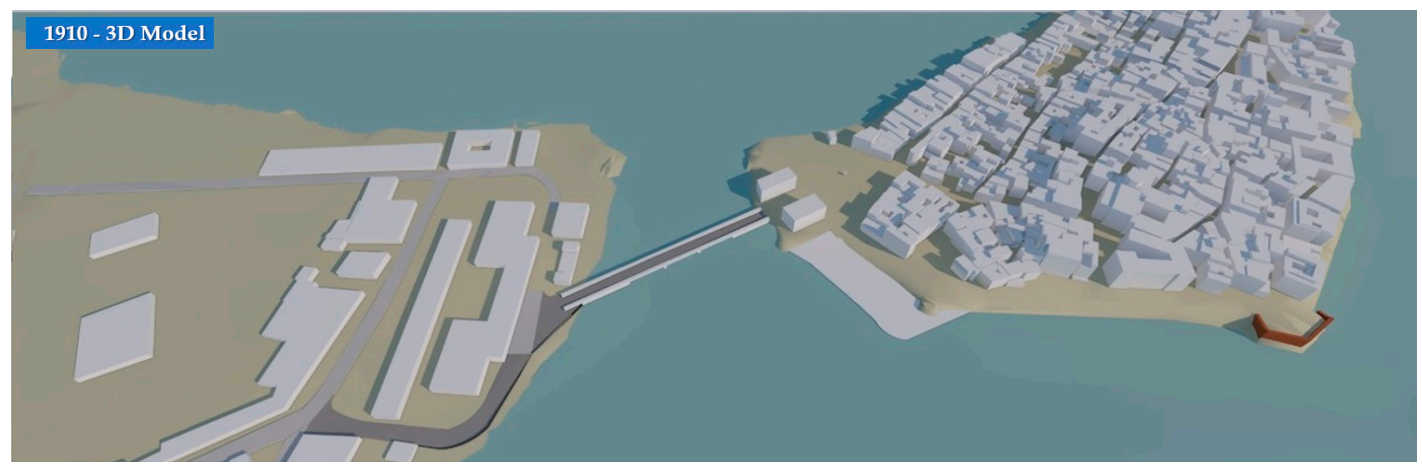

(a)

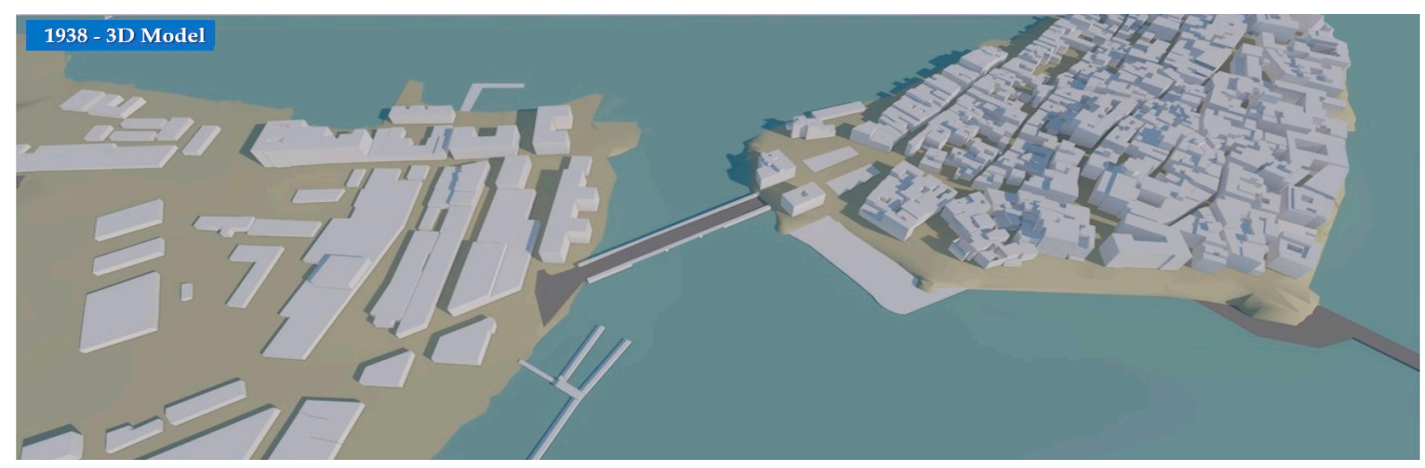

(b)

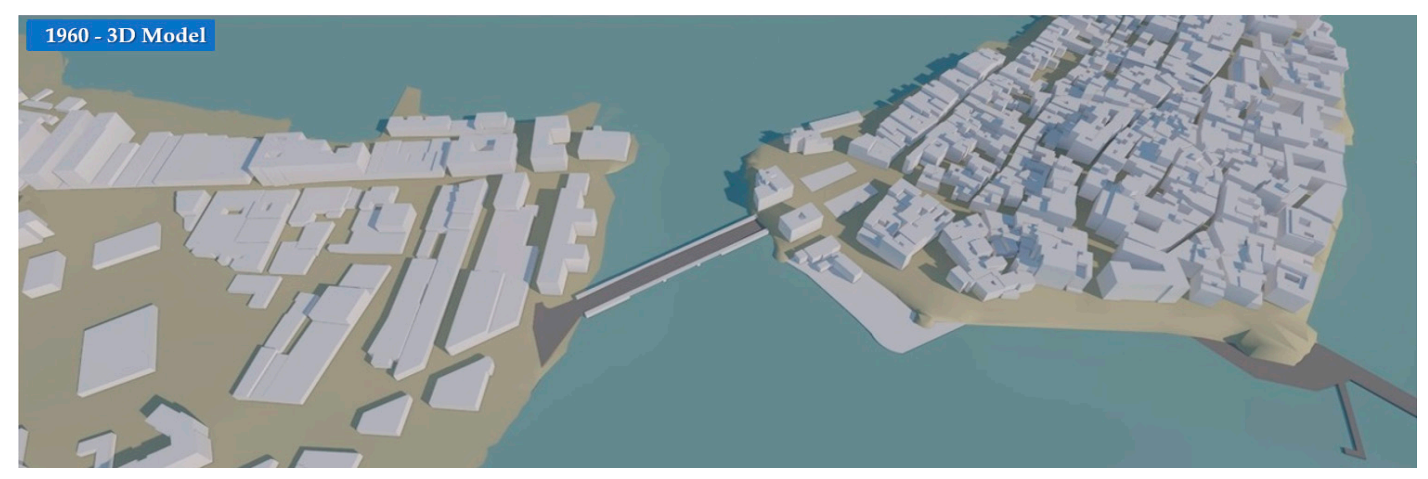

(c)

Figure 13. 3D models: (a) 1910, (b) 1938, (c) 1960.

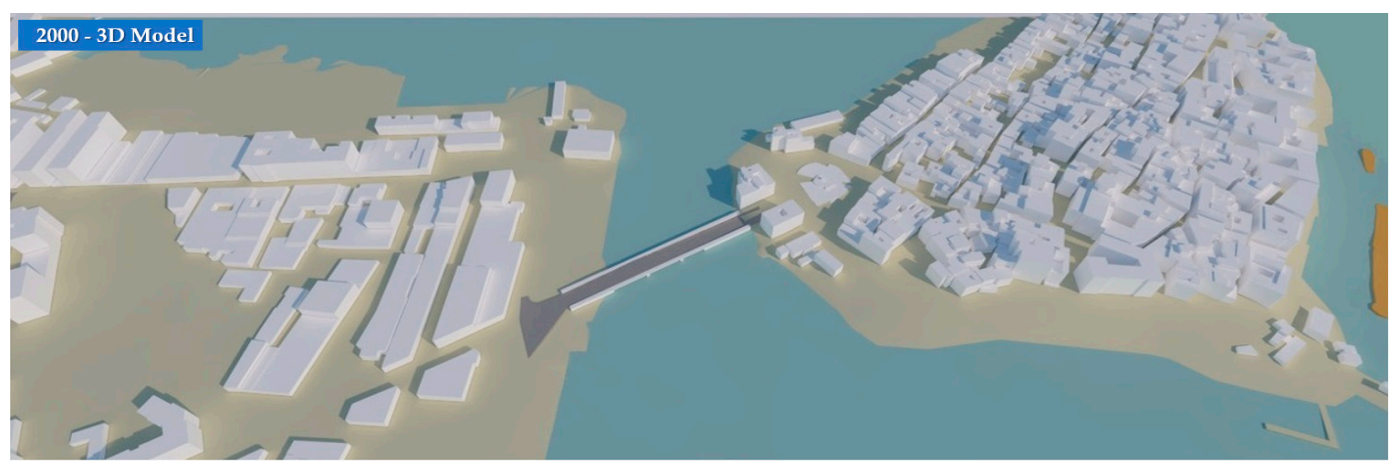

Figure 14. 3D models of the year 2000. 


\subsubsection{Change Detection Analysis}

The volumes obtained in the individual periods were exported in vector format. Then, through a gridding operation, the DSMs of each era were created. In this way, through a difference between the DSMs, it was possible to obtain the variations in the volumes. This task was performed in the ArcGIS environment. In fact, by performing the difference between the raster, it was possible to get the changes between two phases. Figure 15 shows the changes between two successive periods, where in red are highlighted the new buildings and in orange the demolished structures.

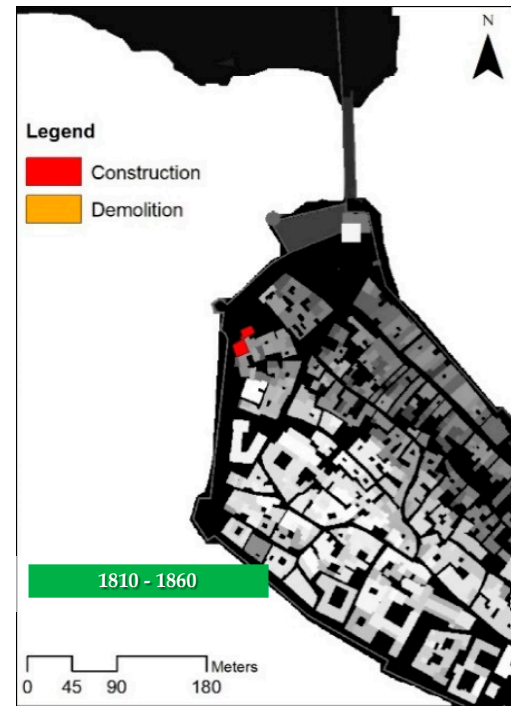

(a)

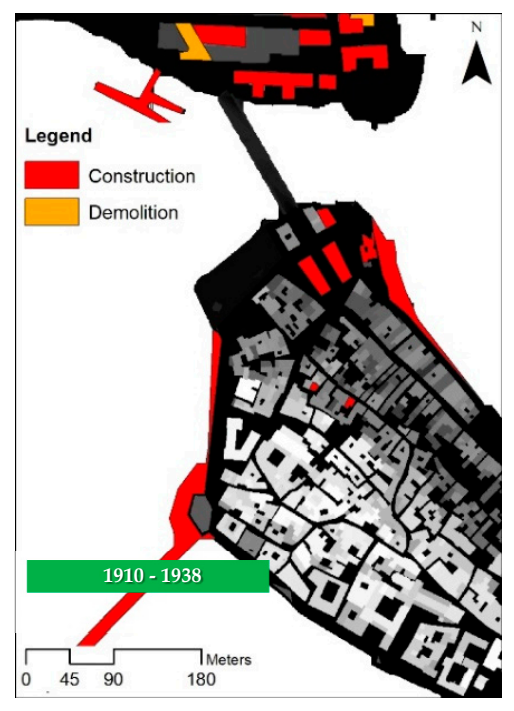

(d)

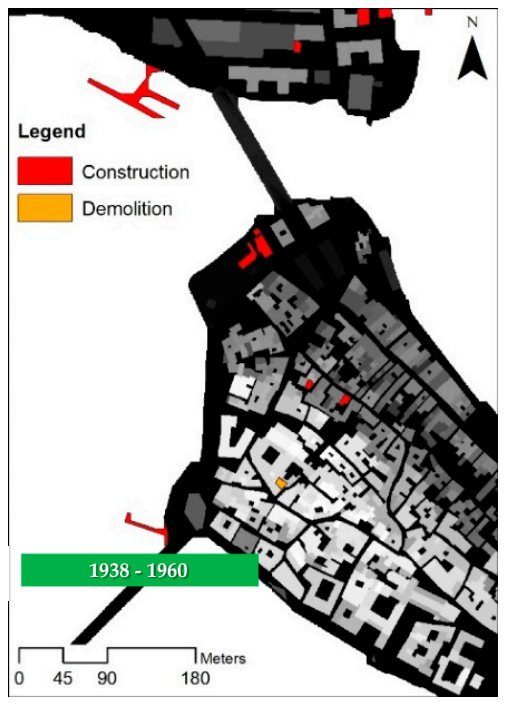

(e)

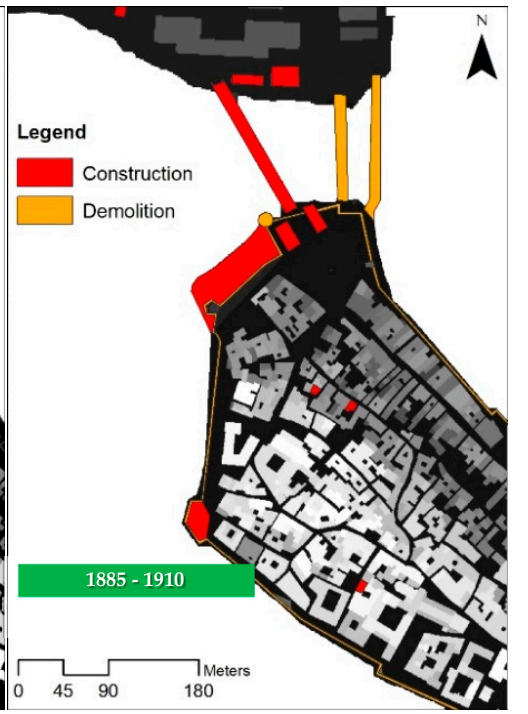

(c)

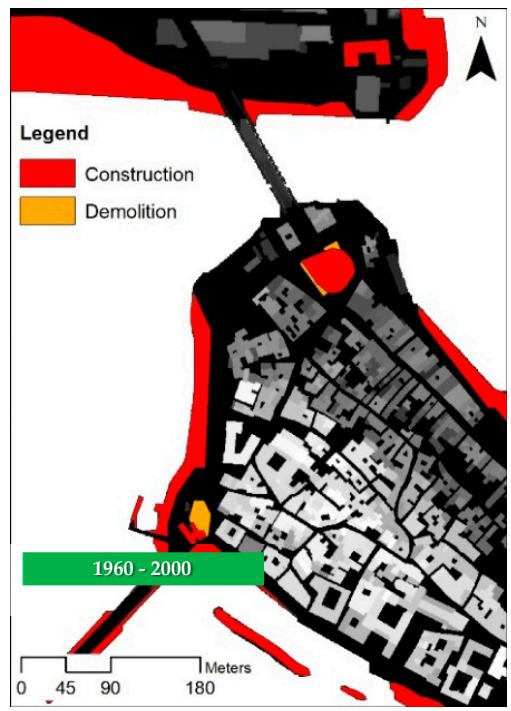

$(\mathbf{f})$

Figure 15. Map of the differences in different eras: (a) from 1810 to 1860, (b) from 1860 to 1885, (c) from 1885 to 1910, (d) from 1910 to 1938, (e) from 1938 to 1960, (f) from 1960 to 2000.

In the period between 1810 and 1860, the conformation of the urban portion concerned remained substantially unchanged (Figure 15a); since 1st September 1865, the Royal Decree freed Taranto of military servitude. The variations in the profile of the coastline found in the comparison of the different plans of those years are negligible; there is no documentation of any substantial change in the profile of the coast, so it was decided to preserve the profile of the early nineteenth century while being aware 
of the natural variations that occurred in such a wide interval of time. The only significant variation in the mainland portion is the construction of the railway station at the head of the Calabro-Sicula line that connected Taranto to Metaponto and the Tyrrhenian side.

In the period between 1860 and 1885, more exactly in 1883, the city of Taranto was hit by a violent flood that created many damages including the collapse of the Porta Napoli bridge.

In the period between 1885 and 1900, the urban aspect remains unchanged in the old town where the demolition works of the walls and fortifications began but proceeded very slowly (Figure 15b). A wooden walkway leading to the city was provisionally built parallel to the old bridge. Another small change concerns the area near the railway station.

The slow process of demolition of the walls and towers ended in the years between 1885 and 1900, and at the beginning of the last century, the ancient settlement was completely devoid of the fortification system (Figure 15c). In the "General plan of the merchant port of Taranto" of 1887, after the collapse of the ancient bridge of Porta Napoli and with the definitive location of the new railway station, a perspective axis of connection between the ancient village and the station was hypothesised. The new bridge was placed on this axis, composed of a system of three arches for a length of about $130 \mathrm{~m}$. Moreover, at the entrance of the old town, at the sides of the new bridge position, two new building volumes were built.

In the period 1900-1938, the area surrounding the station (northern part) was characterised by the development of new building volumes; further, at the entrance of the old town, two building volumes were built. In addition, new quays were built around the old town (Figure 15d).

In the period between 1938 and 1960, the area under investigation did not undergo any particular changes (Figure 15e).

In the last period under consideration (1960-2000), the quays north of the old town underwent major changes. In addition, the entrance of the city is characterized by the demolition of two buildings in place of which a pier is built (Figure 15f).

In order to visualize the differences between volumes built or demolished in different epochs, several 3D models were built (Appendix A).

\subsubsection{Bridge}

Bridges, like buildings, represent an important information layer for the description and management of urban heritage. To connect the old town of Taranto with the mainland, there is a bridge of a particular historical and architectural value, called "Ponte di Porta Napoli". As described in the previous paragraphs, the current configuration is only the latest in a series of structures that have followed one another from the beginning of the nineteenth century to the present day.

The 3D survey of the bridge was carried out with a terrestrial laser scanner (TLS). In particular, laser acquisitions were made using a Leica HDS 3000 laser, which is a system that uses a pulse laser distance meter for measuring lengths and that determines angles by reading the turning of the oscillating plane mirror and of the heading of the scanner. The field of view of the scanner is $360^{\circ}$ in the horizontal direction and $270^{\circ}$ in the vertical direction, and the accuracy declared by the manufacturer is $6 \mathrm{~mm}$ for objects placed at a distance of $50 \mathrm{~m}$.

In order to cover the entire structure of the bridge, eight scans were performed. Obviously, every scan is expressed in its own local reference system, and in this case, an area of overlapping scans must be provided a priori and shadow zones must be avoided. For the georeferencing of the scans, it was essential to carry out a topographical survey to frame the object in a global reference system. This task was carried out using a suitable total station with an integrated GNSS (global navigation satellite system). The data relative to the topographic network acquired on the job were exported, processed and subsequently compensated with the use of the Leica Geosystem Office (LGO) software in order to evaluate the accuracy of the coordinates of the points referring to a single reference system. In particular, the GCPs were calculated in the UTM33-WGS84 reference system. The data obtained from the TLS were processed with the Leica Cyclone software, which is the market-leading point 
cloud processing software. The point clouds (Figure 16a), resulting from the individual acquisitions, were initially assembled to reconstitute the different sides of the bridge. Subsequently, the point clouds thus constituted were assembled based on the previously compensated topographic network, using the targets and natural points recognizable in the scans in order to form a single coherent cloud with a single reference system. The point cloud was imported in the Rhinoceros software in order to build the parametric object of the bridge under investigation. A detailed procedure in order to obtain parametric object starting from the point clouds is described in [24]. In this way, the 3D model of the masonry bridge was performed, as shown in Figure 16b-d.

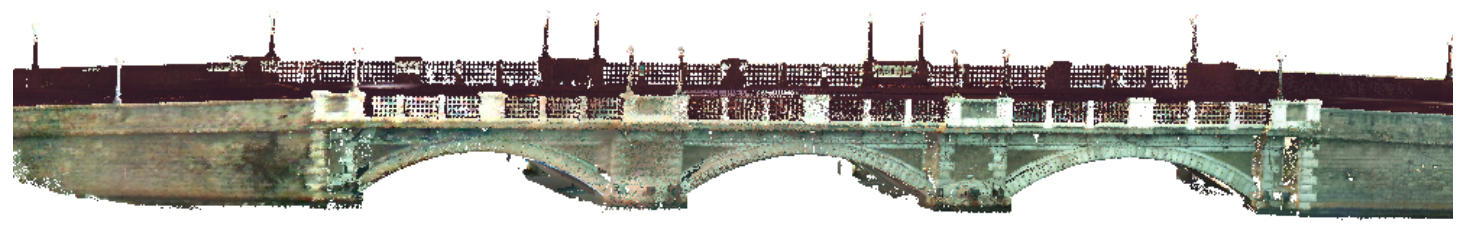

(a)

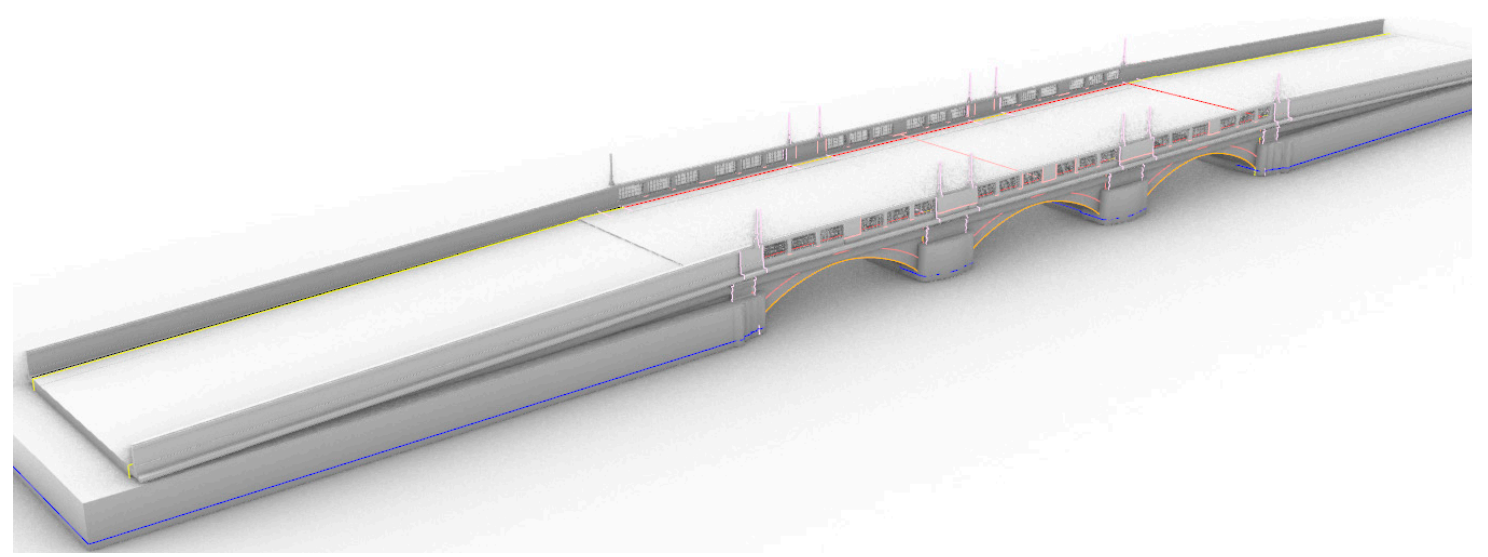

(b)

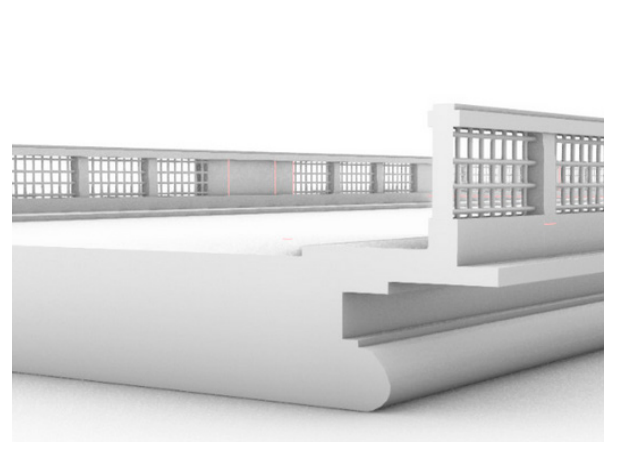

(c)

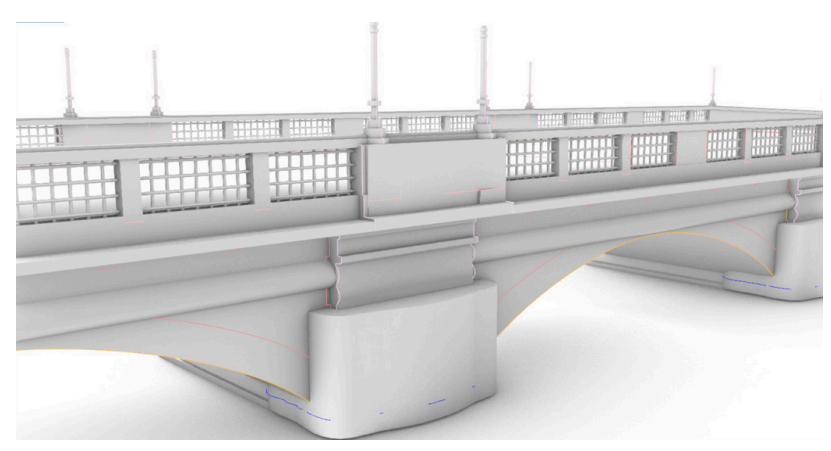

(d)

Figure 16. Three-dimensional representation of the bridge of "Porta Napoli": (a) 3D point cloud; (b) 3D model of the masonry bridge; (c,d) details of the model.

\section{Building CityGML Model}

CityGML is a common information model for the representation, storage and exchange of 3D city model data [25]. A review of some software that allowed to read, write or manage CityGML model is reported below (Table 2). 
Table 2. Common software used in order to manage CityGML data.

\begin{tabular}{lc}
\hline \multicolumn{1}{c}{ Software } & Manufacturer \\
\hline Bentley Map & Bentley Systems \\
CityGRID & UVM SYSTEMS GMBH \\
FME & Safe Software Company \\
CityServer3D & 3DIS GmbH \\
CityBrowser, CityViewer, CityEditor, CityGML2CAD & Fraunhofer Institute for Computer Graphics Rearch (IGD) \\
BS Contact Geo & Bitmanagement Software GmbH \\
3D City Database & Technische Universität München \\
\hline
\end{tabular}

In relation to the features of flexibility, geospatial data management and simplicity in file transformation, the FME software was used in order to build CityGML models. FME is a platform able to manage several geo-spatial data. This software, in order to improve access to data and solve compatibility issues without needing to code anything, allows building customised workflows. A typical workflow in FME first identifies the data that need to be read, and then it assesses how to translate the data and what format to write out the data. In addition, FME allows converting spatial data between many formats, transforming spatial data into a precise data model, integrating multiple different data types into a single data model and sharing spatial data.

\subsection{City GML LOD1 of the Historical Part of the Taranto}

The first feature turned into the CityGML model was the "buildings" feature. Inside the diagram developed in the FME software, the ESRI shapefile was uploaded, which was generated in the ArcMap software. This ESRI shapefile contains several fields:

- "Description" buildings classification (residential, church, etc.);

- "Height" height of the buildings (measured from the ground level) was taken from numerical cartography;

- "Time" time of construction of the buildings.

In the first step of the diagram, using a special "transformer" (a tool) present in the software, called "AttributeFilter", the different categories of buildings are represented. Subsequently, taking into account the specification reported in CityGML, the classes to which the buildings belong were coded. This was possible with the help of a transformer called "AttributeCreator". Since there was a "building height" field in the ESRI shapefile, the buildings were extruded through the use of a special tool developed within FME (extruder). In this way, a 3D model of the buildings was built. Therefore, this model can be exported to other 3D modelling software, or simply for a 3D view of the objects on orthophotos. In fact, since it was possible to create a ${ }^{*} \mathrm{kmz}$ file, it was feasible to verify the geometry of the buildings on Google Earth. Once one has obtained the 3D geometry of the single building, one could generate a 3D city model by the use of the tool "CityGMLGeometrySetter". In this tool, "lod1MultiSurface" was set in "CityGML Lod Name", while "cityObjectMember" was set in "Feature Role". Finally, it was possible to write the building in CityGML format. The pipeline developed in the FME software is shown below (Figure 17).

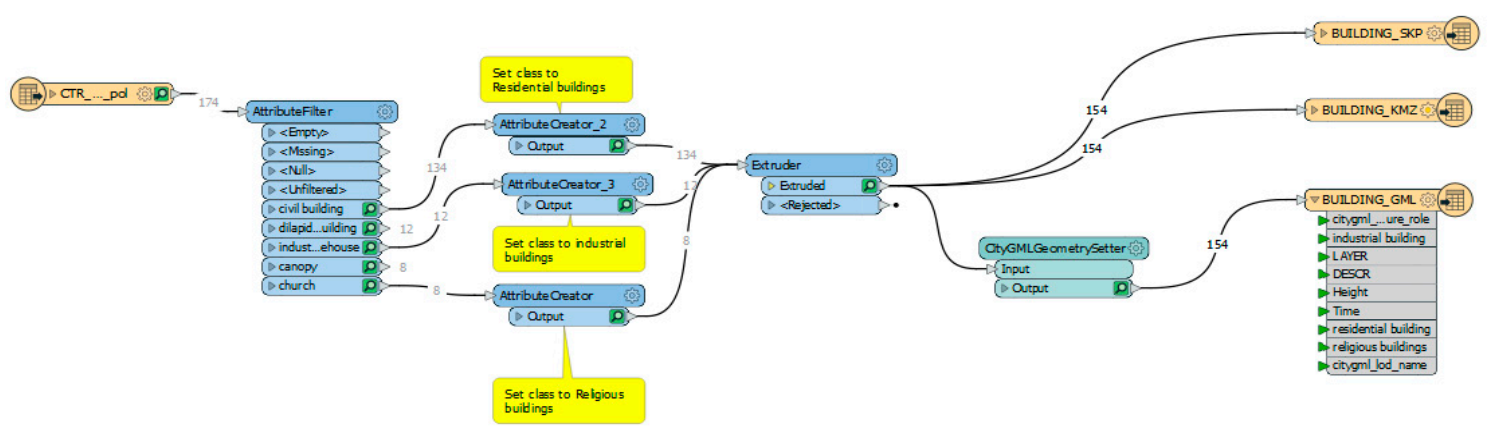

Figure 17. Transformation schema in FME environment to obtain the "building" feature in CityGML format. 
The terrain is represented, in the CityGML, by the class ReliefFeature (in LOD 0-4). The ReliefComponents step of the city GML takes into account four subclasses: break lines, triangulated irregular networks (TINs), mass points and grids (raster). In order to produce the digital terrain model in GML format, the first step was to transform the DTM (raster format) into *LAS format. By the use of the "Triangulator" tool, the points were transformed into a TIN surface. Subsequently, the "GeometryPropertySetter" tool made it possible to set selected geometry names or traits from feature attributes or constants. Finally, "TINrelief" was written according to the CityGML format. However, in order to give a texture to the ground, a colour orthophoto with a geometric resolution of $0.5 \mathrm{~m}$ was used. Starting from the orthophoto in GEOTIFF format, through the use of three transformers, it was possible to write a file in CityGML format. The first transformer is called "clip"; in this way, by using the point cloud as the clipper and the orthophotos as "clippees", all clippees are clipped to the bounding box of the point cloud. Subsequently, the use of "RasterMosaicker" allowed creating a single raster feature from the source orthophotos. Lastly, the use of the "GeometryPropertySetter" tool, allowed to define a texture of the surface. The check of the quality of the produced file was carried out with the help of the FME Data Inspector software, which allows seeing the results (using tables, and $2 \mathrm{D}$ and $3 \mathrm{D}$ maps) of the previous processing.

\subsection{City GML LOD3 of "Ponte di Porta Napoli" Bridge}

The CityGML bridge module allows the representation of the thematic, spatial and visual aspects of bridges and bridge parts in four levels of detail, LOD 1-4. A level of LOD 3 (architectural model) to represent the masonry bridge has been chosen. In the bridge under investigation, we can consider three parts: the part with the three arches as a bridge part of the whole, as well as the other two sections without arches.

It was possible to model the bridge at LoD3 level considering the different elements of the bridge. Pylons, rostrums, arches and bridge abutments are shown in BridgeConstructionElement; bridge superstructures (floor, sidewalks) are in OuterFloorSurface; and parapets and lighting poles are in BridgeInstallations. A representation of the different elements that make up the masonry bridge is shown in Figure 18a. Therefore, the model created within the Rhinoceros software was exported in .dxf (drawing interchange format) format and, consequently, three files were created. In order to perform the transformation into CityGML, the features Bridge, BridgePart, BridgeConstructionElement and BridgeInstallation must be created. Part of the workbench that converts elements of the Bridge Module is illustrated in Figure 18b. To visualise the result of the processing, the model was imported to the FME data inspector (Figure 18c). 


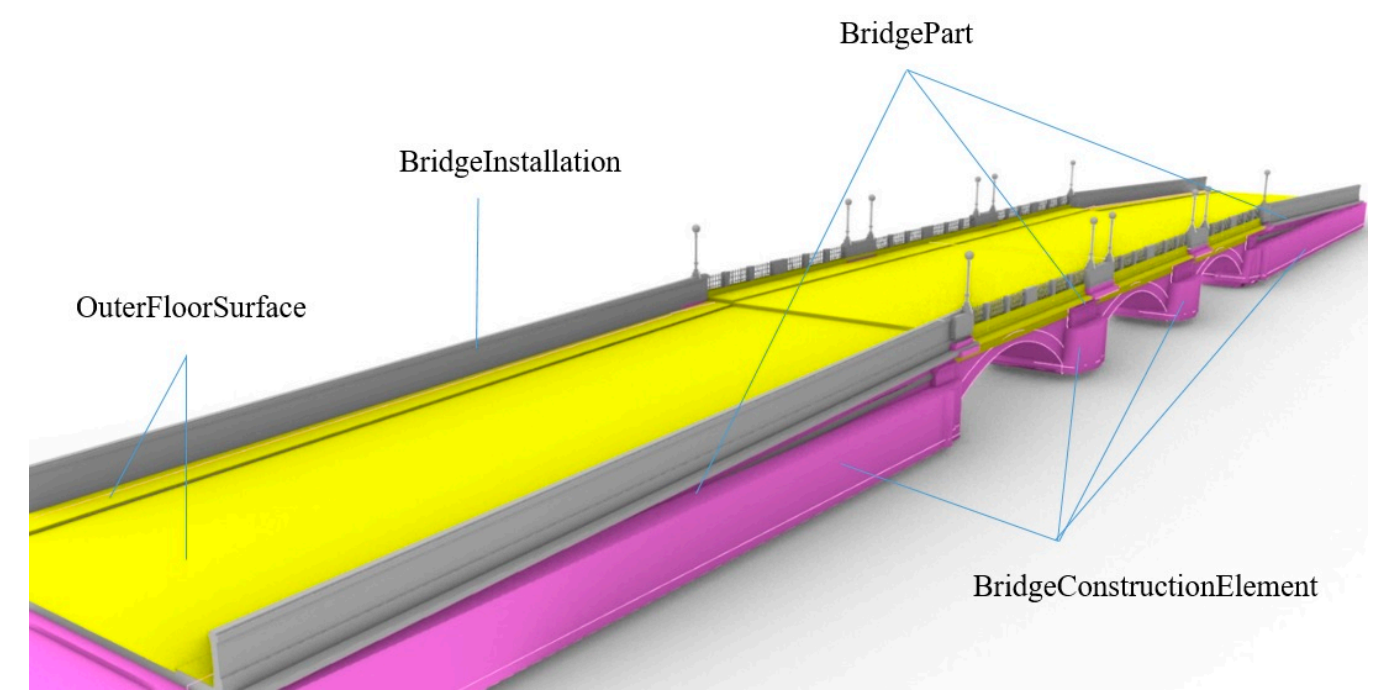

(a)

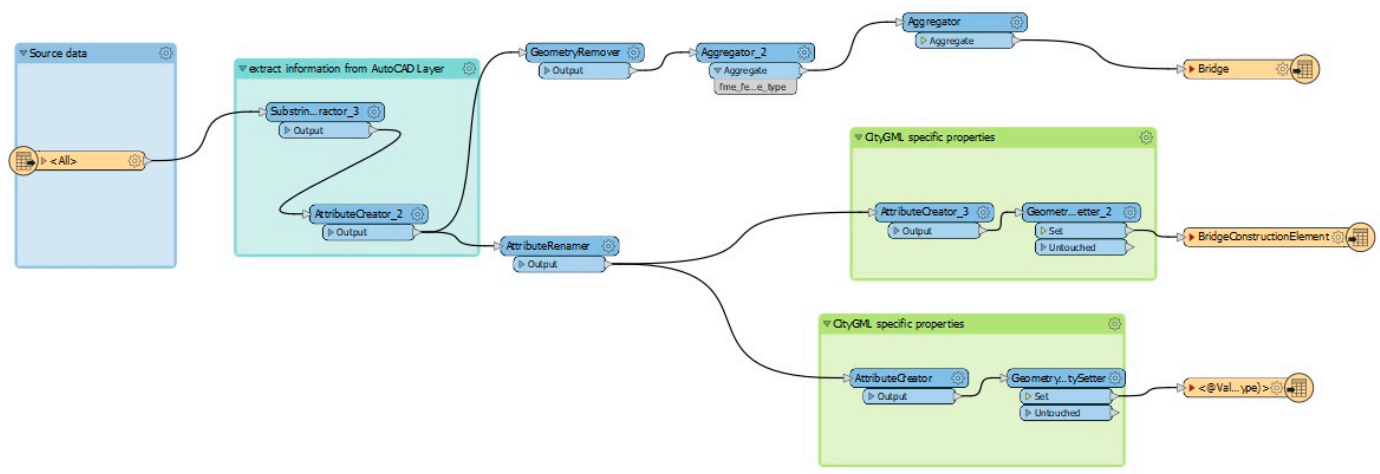

(b)

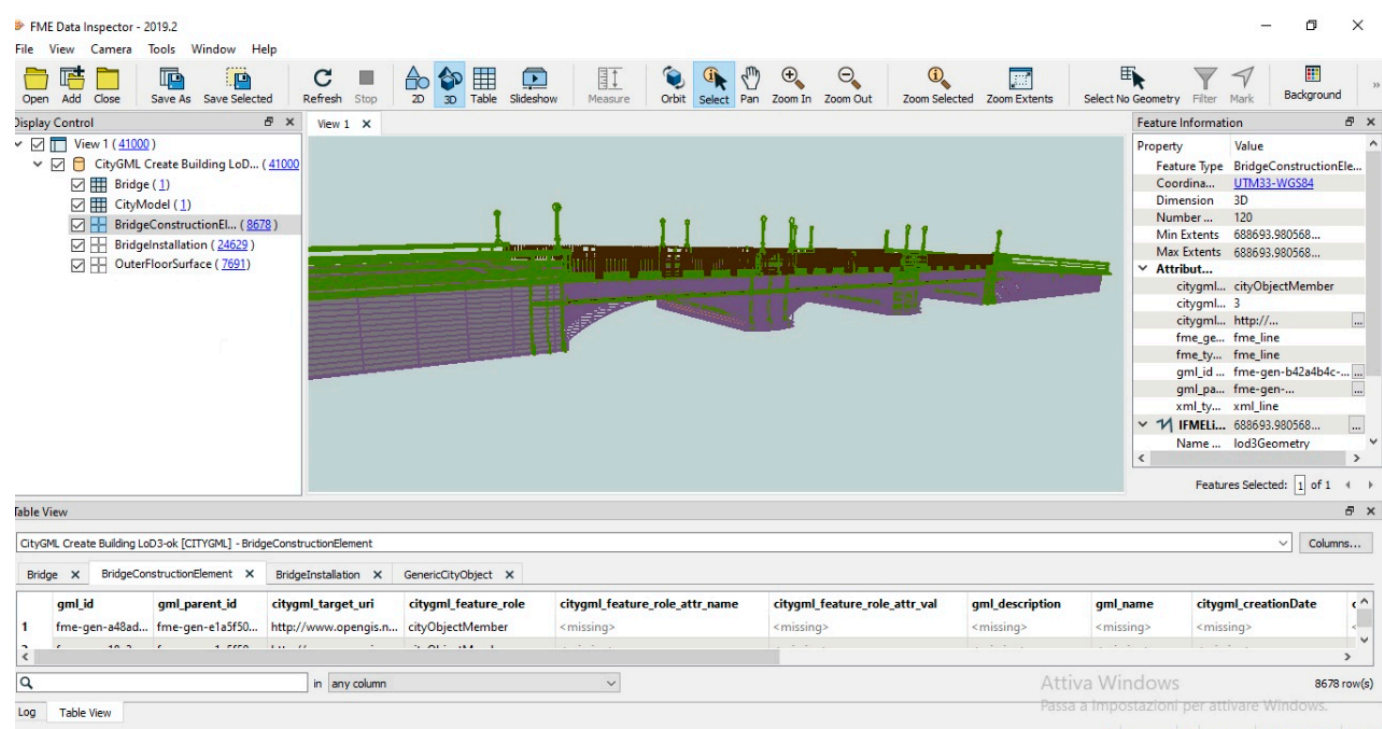

(c)

Figure 18. Building CityGML model: (a) representation of the different elements of the bridge in CiyGML; (b) part of transformation schema in the FME environment to obtain the "building" feature in CityGML format; (c) 3D model in FME data inspector. 


\section{Discussion and Conclusions}

Through the implementation of a 3D city model, it has been possible to highlight the anthropic changes in the historical centre of the city of Taranto, to classify territorial objects with particular attention to monumental buildings and specially to describe their elements according to an appropriate level of detail. In fact, for the historical centre, a CityGML with LOD1 level of detail was realised, whereas for a structure of historical architectural interest, as shown for the "Ponte di Porta Napoli", an LOD3 has been created.

The approach described in this paper can be applied to the entire urban structure of the city allowing the creation of an IT tool for immediate visualisation and appropriate technical knowledge, aimed at the management and conservation of the area under investigation.

The CityGML represents, therefore, an important tool for sharing georeferenced, territorial and structural information, which are important in the definition of the different levels of intervention by administrations, individuals and bodies responsible for the protection, conservation and maintenance of urban elements.

This article described a procedure transforming the territorial information implemented through ESRI shapefiles into CityGML for the urban part (LOD1). In addition, it described the transformation of the bridge model, designed in the Rhinoceros software, exported in dxf file and, subsequently, transformed into CityGML (LOD3). It has been possible to carry out this task by the FME commercial software that, with a specific proprietary programming language, has allowed describing the spatial objects according to a planned level of detail. However, these processes are rather complex and not easy to manage by users. Hopefully, more simplified routines will be available in the future, preferably in open source mode.

Author Contributions: Conceptualization, Massimiliano Pepe, Domenica Costantino, Vincenzo Saverio Alfio, Maria Giuseppa Angelini. and Alfredo Restuccia Garofalo; methodology, Massimiliano Pepe, Domenica Costantino, Vincenzo Saverio Alfio, Maria Giuseppa Angelini. and Alfredo Restuccia Garofalo; validation, Massimiliano Pepe, Domenica Costantino, Vincenzo Saverio Alfio, Maria Giuseppa Angelini. and Alfredo Restuccia Garofalo; writing - review and editing, Massimiliano Pepe, Domenica Costantino, Vincenzo Saverio Alfio, Maria Giuseppa Angelini and Alfredo Restuccia Garofalo. All authors contributed equally to the research and writing of the manuscript. All authors have read and agreed to the published version of the manuscript.

Funding: This research received no external funding.

Acknowledgments: We want to thanks the reviewers for their careful reading of the manuscript and their constructive remarks. This research was carried out in the project: PON "Ricerca e Innovazione" 2014-2020 A. I.2 D.M. n. 407-27/02/2018 AIM “Attraction and International Mobility" (AIM1895471-Line 1).

Conflicts of Interest: The authors declare no conflict of interest. 


\section{Appendix A}

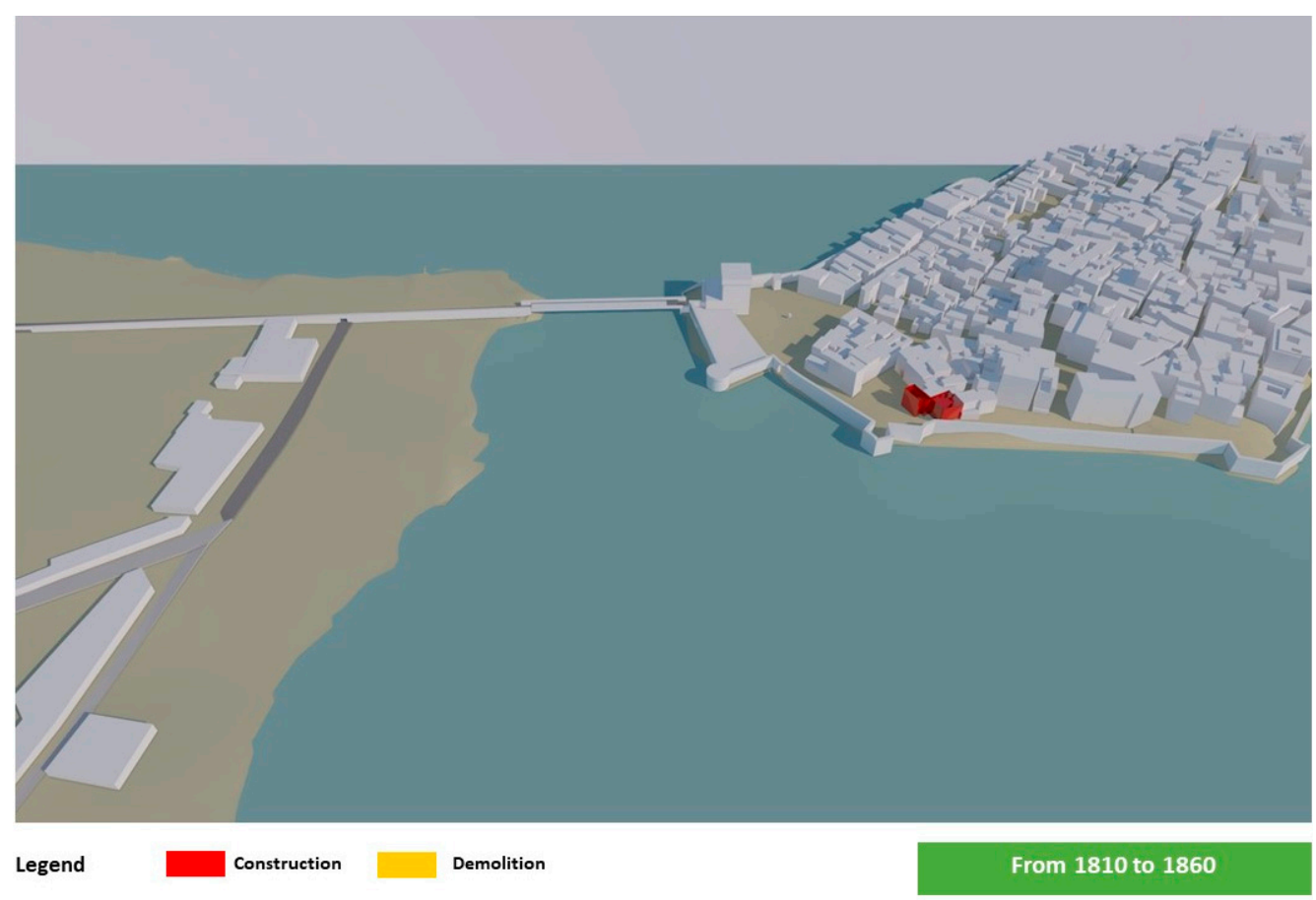

Figure A1. Three-dimensional model of differences between volumes built or demolished—from 1810 to 1860 .

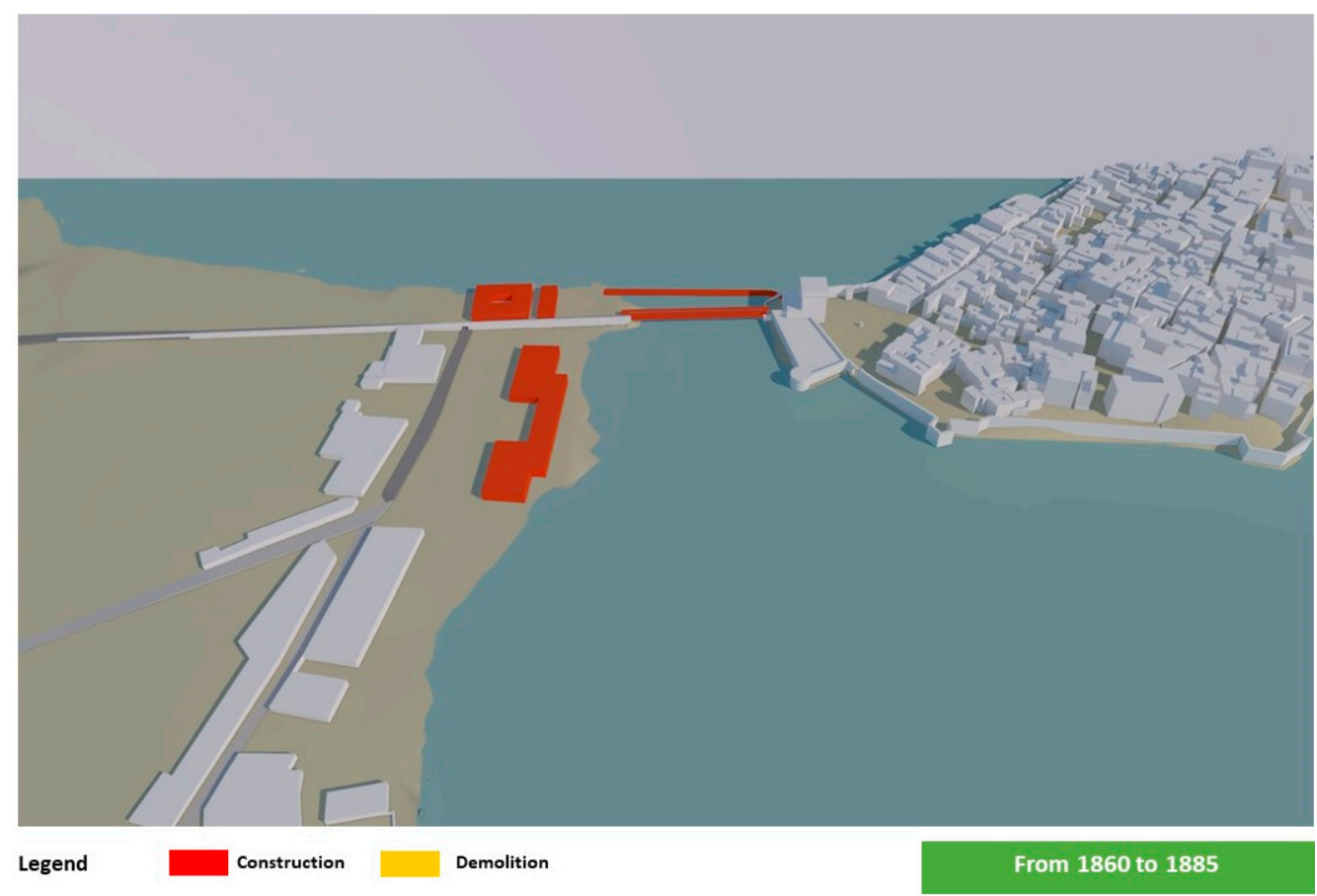

Figure A2. Three-dimensional model of differences between volumes built or demolished—from 1860 to 1885 . 


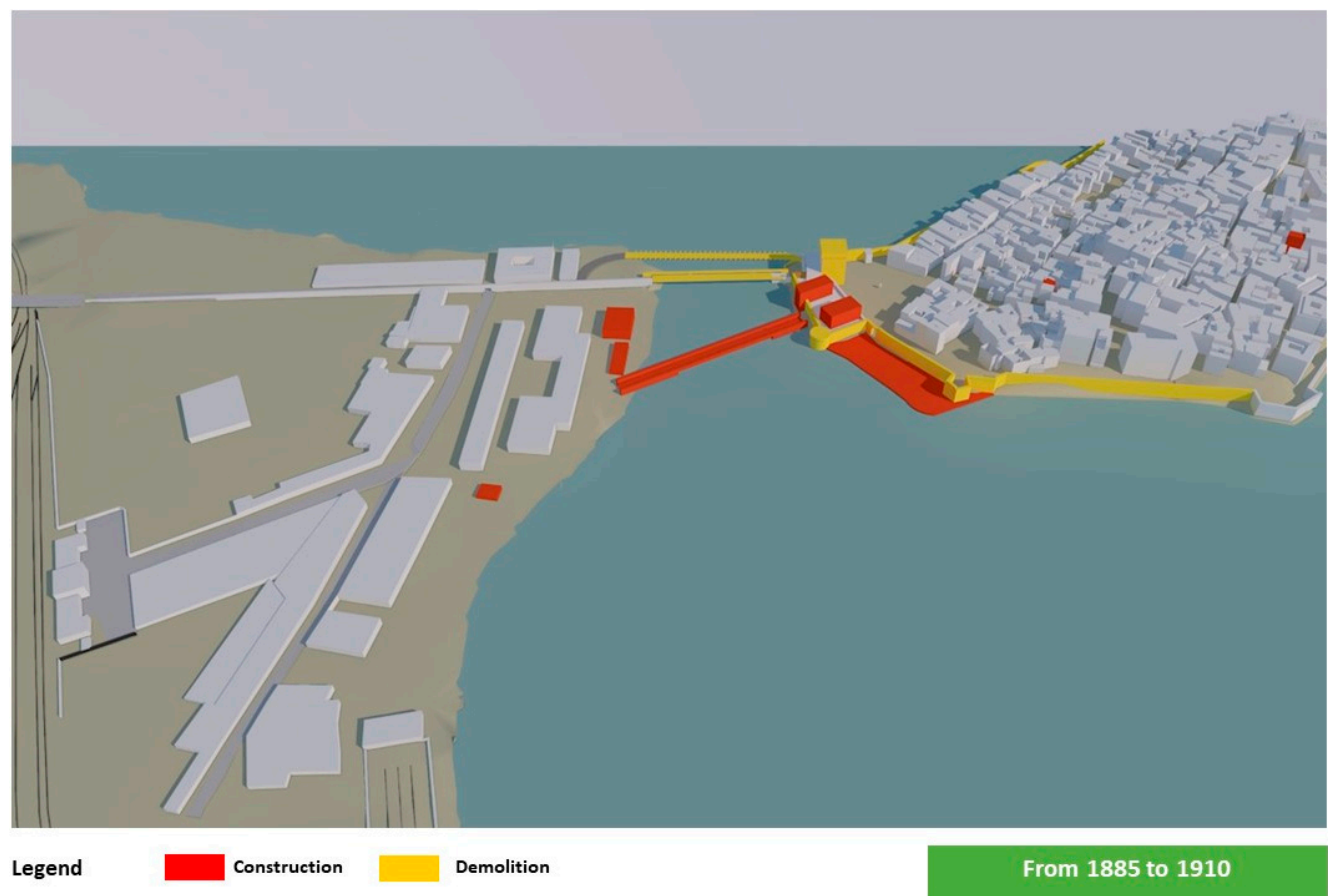

Figure A3. Three-dimensional model of differences between volumes built or demolished—from 1885 to 1910.

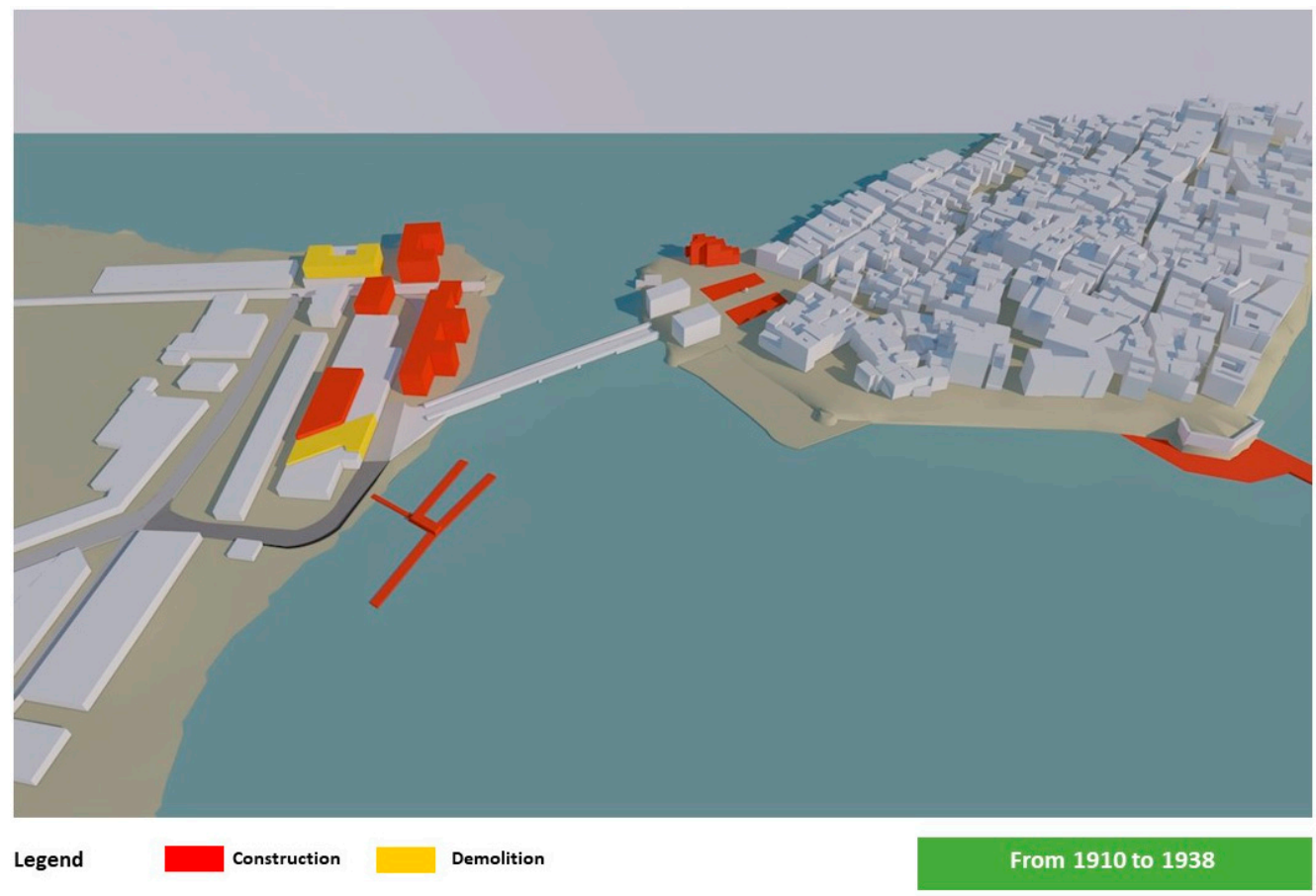

Figure A4. Three-dimensional model of differences between volumes built or demolished—from 1910 to 1938. 


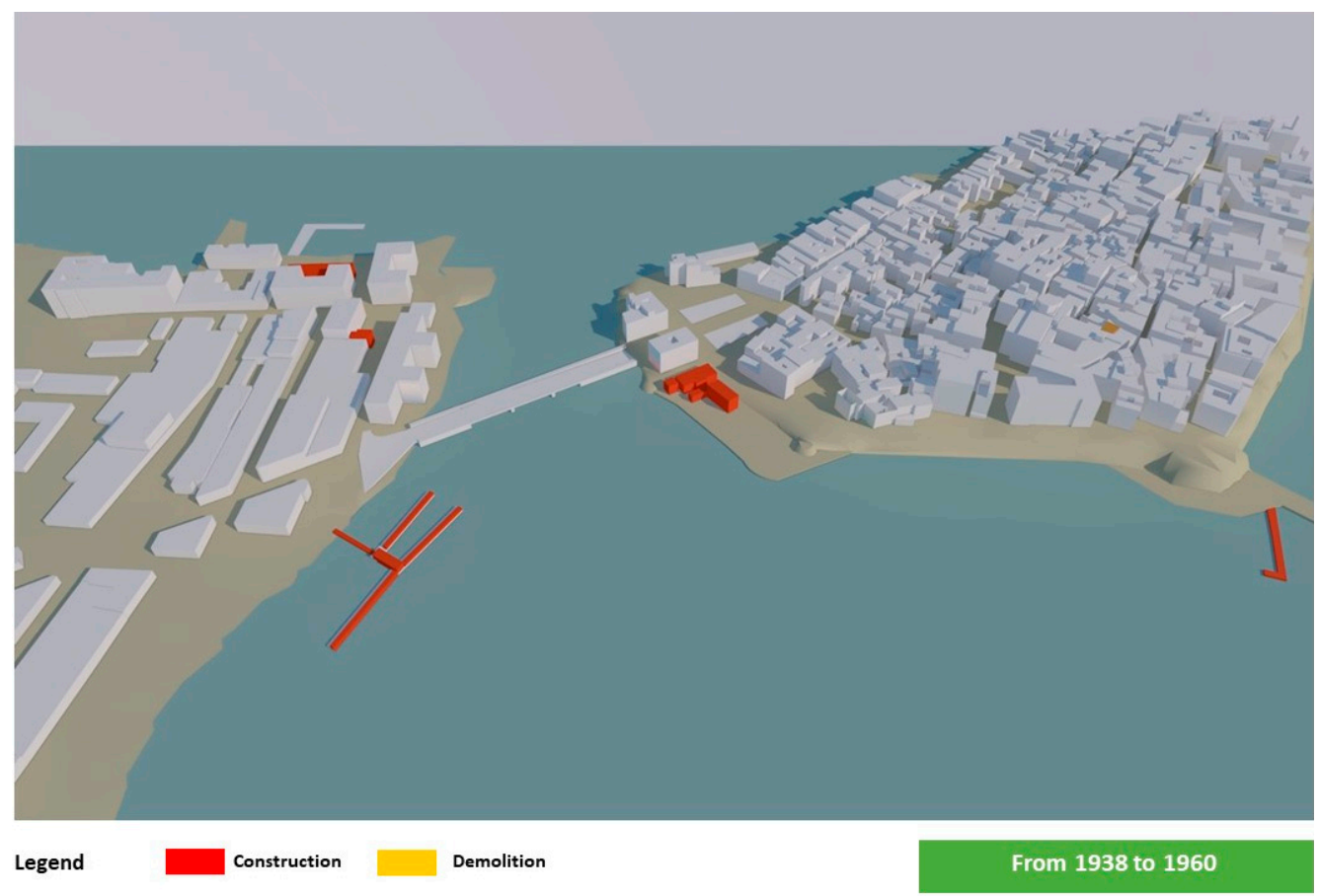

Figure A5. Three-dimensional model of differences between volumes built or demolished-from 1938 to 1960.

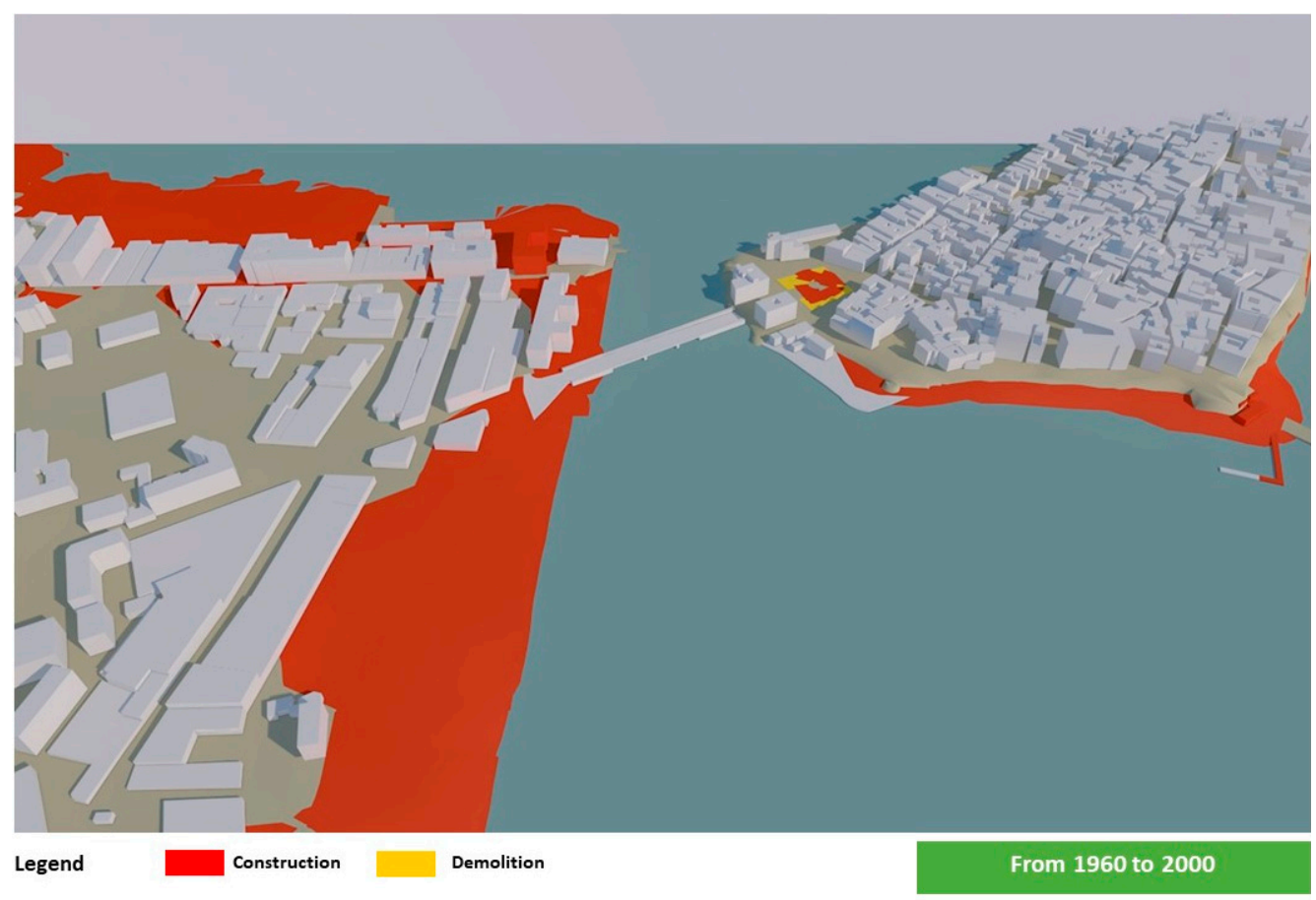

Figure A6. Three-dimensional model of differences between volumes built or demolished—from 1960 to 2000 . 


\section{References}

1. Masi, A.D. Smart Cultural heritage and open source as regeneration of historical centers: Fruition, conservation and preservation in current methods of 2D/3D digitization and 3D modeling. In Proceedings of the IEEE Fourth International Conference on Big Data and Cloud Computing, Sydney, Australia, 3-5 December 2014; pp. 729-736.

2. Guzmán, P.C.; Pereira Roders, A.R.; Colenbrander, B.J.F. Bridging the gap between urban development and cultural heritage protection. In Proceedings of the 34th Annual Conference of the International Association for Impact Assessment, Enjoy Hotel and Casino, Valparaíso, Chile, 8-11 April 2014; pp. 1-6.

3. Ledoux, H.; Meijers, M. Topologically consistent 3D city models obtained by extrusion. Int. J. Geogr. Inf. Sci. 2011, 25, 557-574. [CrossRef]

4. Haala, N.; Rothermel, M. Extracting 3D urban models from oblique aerial images. In Proceedings of the Joint Urban Remote Sensing Event, Lausanne, Switzerland, 30 March-1 April 2015; pp. 1-4.

5. Pepe, M.; Fregonese, L.; Crocetto, N. Use of SFM-MVS Approach to Nadir and Oblique Images Generated throught Aerial Cameras to Build 2.5 D Map and 3D Models in Urban Areas. Geocarto Int. 2019, 1-17. [CrossRef]

6. Haala, N.; Peter, M.; Kremer, J.; Hunter, G. Mobile LiDAR mapping for 3D point cloud collection in urban areas-A performance test. Int. Arch. Photogramm. Remote Sens. Spat. Inf. Sci. 2008, 37, 1119-1127.

7. Nebiker, S.; Cavegn, S.; Loesch, B. Cloud-Based geospatial 3D image spaces-A powerful urban model for the smart city. ISPRS Int. J. Geo-Inf. 2015, 4, 2267-2291. [CrossRef]

8. Open Geospatial Consortium. City Geography Markup Language (Citygml) Encoding Standard Version 2.0.0. Available online: http://www.opengis.net/spec/citygml/2.0 (accessed on 21 October 2019).

9. Gröger, G.; Kolbe, T.H. OGC City Geography Markup Language (CityGML) Encoding Standard; Open Geospatial Consortium Inc.: Wayland, MA, USA, 2012.

10. Kolbe, T.H. Representing and exchanging 3D city models with CityGML. In 3D Geo-Information Sciences; Springer: Berlin/Heidelberg, Germany, 2009; pp. 15-31.

11. Agugiaro, G. First steps towards an integrated CityGML-based 3D Model of Vienna. ISPRS Ann. Photogramm. Remote Sens. Spat. Inf. Sci. 2016, 3. [CrossRef]

12. Janečka, K. Transformation of 3D geospatial data into CityGML-A case of Prague. Rep. Geod. Geoinform. 2019, 107, 41-48. [CrossRef]

13. Abdul Rahman, A.; Rashidan, H.; Musliman, I.A.; Buyuksalih, G.; Bayburt, S.; Baskaraca, P. 3D Geospatial Database Schema for Istanbul 3D City Model. In Proceedings of the 6th International Conference on Geomatics and Geospatial Technology, Kuala Lumpur, Malaysia, 1-3 October 2019.

14. Malinverni, E.S.; Tassetti, A.N. GIS-based smart cartography using 3D modeling. In Proceedings of the ISPRS 8th 3DGeoInfo Conference \& WG II/2 Workshop, Istanbul, Turkey, 27-29 November 2013.

15. Occhinegro, U. The Old Town of Taranto: Architectural Reading of the Historic Urban Form for the Correct Methodology for Restoration Project the Built Heritage in the Island. In Proceedings of the 2nd ICAUD International Conference in Architecture and Urban Design, Epoka University, Tirana, Albania, 8-10 May 2014; pp. 1-9.

16. Pacelli, G. Atlante Sallentino; Cavallino, Biblioteca nazionale Sagarriga Visconti-Volpi: Bari, Italy, 1986.

17. Speziale, G.C.; Croce, B. Storia Militare Di Taranto Negli Ultimi Cinque Secoli; Gius. Laterza \& Figli Tip.: Bari, Italy, 1930.

18. Gagliardo, G.B. Descrizione Topografica Di Taranto: Con Quella Dei Suoi Due Mari; Biblioteca civica Pietro Acclavio: Taranto, Italy, 1811.

19. Carlone, G.; Blasi, O. La Provincia Di Taranto, Atlante Storico Della Puglia; Cavallino: Lecce, Italy, $1987 ;$ Volume 3.

20. Luhmann, T.; Robson, S.; Kyle, S.; Harley, I. Close Range Photogrammetry: Principles. Methods and Applications; Whittles Publishing: Caithness, UK, 2006; p. 528.

21. Pepe, M. A survey by Airborne Laser Scanner of open large structure: A case study of Pompeii Amphitheatre. ARPN J. Eng. Appl. Sci. 2017, 12,1-11.

22. National Geoportal of the Ministry of the Environment. Available online: http://www.pcn.minambiente.it/ mattm/tag/dati-lidar/ (accessed on 16 March 2020).

23. Global Mapper L.L.C. Global Mapper Version 9.0 Software; Global Mapper: Parker, CO, USA, 2009. 
24. Pepe, M.; Costantino, D.; Restuccia, A.G. An Efficient Pipeline to Obtain 3D Model for HBIM and Structural Analysis Purposes from 3D Point Clouds. Appl. Sci. 2020, 10, 1235. [CrossRef]

25. Gröger, G.; Plümer, L. CityGML-Interoperable semantic 3D city models. ISPRS J. Photogramm. Remote Sens. 2012, 71, 12-33. [CrossRef]

(C) 2020 by the authors. Licensee MDPI, Basel, Switzerland. This article is an open access article distributed under the terms and conditions of the Creative Commons Attribution (CC BY) license (http://creativecommons.org/licenses/by/4.0/). 